\title{
Climatological Assessment of Urban Effects on Precipitation at St. Louis
}

\author{
F. A. Huff and S. A. Changnon, JR. \\ Illinois State Water Survey, Urbana 61801 \\ (Manuscript received 13 December 1971, in revised form 13 March 1972)
}

\begin{abstract}
An investigation was made of urban effects on precipitation in and downwind of St. Louis through use of long-term climatic records within a radius of $50-75 \mathrm{mi}$ of the city. Based upon radar climatological studies, two potential urban effect areas and two no-effect (control) areas were designated. Analyses were then performed to assess the urban effect on 1) total monthly and seasonal precipitation; 2) the frequency and intensity of daily precipitation; 3) the frequency of thunderstorms, hailstorms, and severe rainstorms; 4) wet-dry period rainfall; and 5) weekday-weekend precipitation (indicator of industrial-induced effect). Evidence of urban effects was found in all seasons, but appear to be strongest in late spring and summer. Results indicated an urban-induced increase in average summer rainfall ranging from 6 to $15 \%$ for distances up to $25 \mathrm{mi}$ downwind of the city. The urban-increase mechanism apparently is most active on days of moderate to heavy intensities in the natural rainfall. The urban effect was most pronounced in relatively wet summers, and indications of a suppression effect were found in dry summers. Evidence was found of an urban-induced increase in thunderstorm days within the city and of hail-day maxima downwind of the city. Overall, results appear to support thermal effects as the most important causative factor for urban modification of the natural precipitation distribution.
\end{abstract}

\section{Introduction}

Extensive climatological analyses of urban effects on precipitation conditions are being carried out under National Science Foundation sponsorship using historical data in and around eight major cities in central and eastern United States. Long-term records of precipitation, thunderstorms, hail, and related weather conditions are being examined to establish the existence of urban effects on precipitation, including both spatial and temporal changes; the likely causes of any detectable changes; and the difference in changes wrought by varying urban areas chosen to represent different climatic zones, industrial complexes, geophysical sites, and growth rates in the 20th century. Cities involved include St. Louis, Chicago, Indianapolis, Cleveland, Washington D. C., Houston, New Orleans and Tulsa. The motivation for this research came largely from earlier results at La Porte, Ind., and Chicago (Changnon 1968, 1969) which indicated urban-related rain, thunder and hail increases downwind of Chicago and other cities.

\section{a. Purpose and scope}

In the climatological study for St. Louis and each of the other cities, analyses were made initially of monthly, seasonal and annual precipitation within a radius of 50-75 mi of the city, in order to establish whether any unusual values potentially related to urban effects appear to be present. When such was the case, a more extensive analysis was then made of weekday- weekend occurrences of precipitation (evidence of industrial-induced effect), number of precipitation days in various intensity categories, frequency of thunderstorm and hail days, thunderstorm rainfall amounts, heavy rainstorm occurrences, diurnal distributions, and synoptic weather types responsible for the urban anomaly. Thus, the objective was not only to identify any urban-related rain effect, but also to describe its characteristics in different seasons, under various meteorological conditions, and in the presence of different urban conditions. Thorough study of the urban effect on precipitation conditions (inadvertent weather modification) should provide valuable information and guides to planned weather modification efforts. This paper summarizes results of the climatological study at St. Louis and indicates the presence of an urban precipitation effect of substantial magnitude. Emphasis will be placed upon summer when the urban effect appears to be most pronounced. Results of this study were instrumental in establishing an extensive field study of inadvertent weather modification in the St. Louis region which was initiated in June 1971 (Changnon et al., 1971).

\section{b. Potential causes of urban effects}

Urban-induced changes in the natural precipitation could result from four potential modifications of the atmosphere. These include 1) atmospheric destabilizing from the output of the well-established urban heat island, 2) modification of microphysical and dynamical 


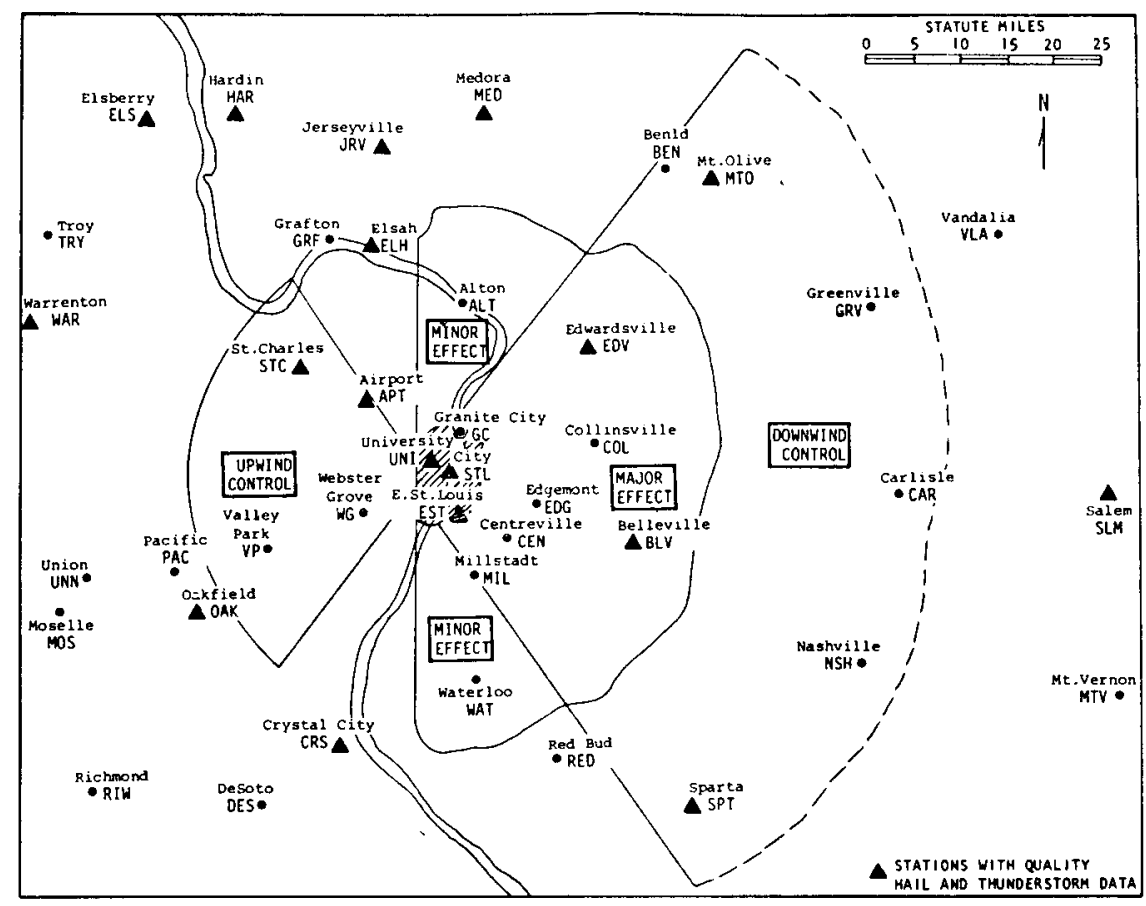

FIg. 1. Climatic stations and areas used in urban-effect studies.

processes in passing clouds through addition of condensation and ice nuclei from industrial discharges, 3) increase of low-level mechanical turbulence from urban-created obstructions to airflow, and 4) modification of the low-level atmospheric moisture content by additions from industrial-generated plumes emitted from stacks and cooling towers, along with changes in the natural evapotranspiration process within the city resulting from the large percentage of impervious surface in central urban areas.

\section{c. Selection of St. Louis}

This city was selected as a representative midwestern city with an industrial complex that is large and varied. It includes a mixture of most of the basic industries, such as steel, petroleum and chemicals, plus light and heavy manufacturing. Furthermore, any urban-induced rainfall could be economically important, since a very permeable area is located a few miles downwind of the city where rainwater recharge of groundwater is very important to local industrial and public water supplies. The city lies on the west bank of the Mississippi River with its industry concentrated along the river east of the urban center. It has an urban population of 619,000 and a total metropolitan area population of 2,355,000 according to the 1970 census. The city is located in the flatlands of the Mississippi River Valley (400-700 ft MSL) but is subjected to possible topographic effects on storms approaching from the Ozarks to the SW and $W$. The terrain is relatively flat $\mathrm{S}, \mathrm{E}, \mathrm{N}$ and $\mathrm{NW}$ of the city; however, abrupt changes in relief of 50 to $150 \mathrm{ft}$ do occur at the river bluffs a few miles east of the city. The terrain becomes hilly SW and W of the city in the Ozark foothills with a few elevations of $1000 \mathrm{ft}$ or more at distance of 20-25 mi from St. Louis.

\section{d. General climate}

With its continental humid climate, St. Louis is subjected to extremes of precipitation, temperature, and various forms of severe local weather. The AprilJune period is normally the wettest with frequent thunderstorms and an average rainfall of 12 inches. Dry periods occur frequently from midsummer to fall when it is not unusual to have periods of 1-2 weeks or more without appreciable rainfall. Snowfall averages less than 20 inches per year. Annual precipitation averages about 37 inches in the city.

\section{Analytical procedures}

A major problem in studying urban effects is defining the area of potential effect. In the St. Louis study, the built-up urban zone including its industrial complex was selected as the region having potential effects on all passing precipitation systems. Passing convective precipitation cells presumably affected by urbanindustrial factors were then modeled through use of cell durations, speeds and motions, based upon findings of Byers and Braham (1949) and Towery and Changnon (1970). This resulted in a model storm with a speed of $22 \mathrm{mph}$ and an average travel distance of $26 \mathrm{mi}$. An analysis of directions of 153 storm motions in Illinois 
(Towery and Changnon, 1970) revealed that $92 \%$ came from the SW, WSW, W, WNW or NW and only $8 \%$ from the NNW, N, SSW and S. Studies of motions of precipitation lines (Changnon and Huff, 1961) revealed that $84 \%$ came from directions within an arc from $225^{\circ}$ clockwise through $315^{\circ}$ (SW-NW).

It was assumed that the precipitation process in a storm element is affected throughout the time it is over the St. Louis urban-industrial area (hashed area in Fig. 1), and that the effect persists until the element dissipates. Thus, an average "effect area" was constructed using the 26-mi distance to define the outer or downwind limit. A storm element having crossed $4 \mathrm{mi}$ or more $(10 \mathrm{~min}$ at average speed of $22 \mathrm{mph}$ ) of the urban-industrial area was considered to have experienced a near-maximum of the possible effect of the total urban area. A $110^{\circ}$ sector was derived from consideration of the primary precipitation motion values and requisites of a 4 -mi over-city travel. The area within $26 \mathrm{mi}$ of the eastern urban edge and within the $110^{\circ}$ sector was then defined as the Major Effect Area (Fig. 1). The urban complex and those areas to the N, NNE, SSE and $S$ that are downwind for infrequent storm motions were defined as the Minor Effect Area.

An Upwind Control Area was chosen to match the general size and shape of the Major Effect Area (Fig. 1). Also, a Downzeind Control Area with a comparable depth and a fanshape extending from the Major Effect Area was established. Both of these were defined as no-effect areas. Stations outside of the effect and no-effect regions shown in Fig. 1 were used to assist in establishing spatial precipitation patterns and in interpreting the significance of urban-related patterns. Although there were several arbitrary decisions involved in the modeling and subsequent definition of the areas, they are considered reasonable approximations that are useful for comparing regional differences.

Two types of precipitation analyses were employed in the evaluation of urban effects: 1) the usual expression of station precipitation values in inches, and 2) precipitation ratios, in which the precipitation (monthly or seasonal) at each station was divided by the average precipitation for the two urban stations designated STL and UNI in Fig. 1. This simple normalization technique facilitated evaluation of time trends in urban effects, especially during periods of a climatologically generated upward or downward trend in precipitation extending throughout the effect and no-effect areas. Furthermore, the ratios provide a simple measure of the magnitude of any urban-induced downwind effect.

In the time-trend analyses, 2- and 5-year moving averages of monthly and seasonal precipitation were used to smooth out some of the year-to-year natural variability in the data, in order to facilitate evaluation of any long-term trends. The moving averages in conjunction with the ratios were particularly useful in delineating potential urban effects in the precipitation time series for a given month or season.
Earlier studies indicated urban-related increases in thunderstorm occurrences at Chicago (Changnon, 1969) and sizable increases in both thunderstorm and hailstorm frequencies in and around La Porte, Ind., downwind of the south Chicago industrial complex (Changnon, 1968). Hence, a similar investigation was undertaken in the St. Louis area, based primarily upon comparative analyses of thunder-day and hail-day events. Rainfall and synoptic weather conditions were analyzed also in conjunction with certain phases of the thunderstorm study. Analyses were restricted largely to seasonal and annual frequencies. Point comparisons were made on a temporal basis for stations with long periods of quality records. Areal means were used to compare thunderstorm-hail frequencies upwind and downwind of the urban area. Also, data for the two first-order stations at St. Louis (STL, APT) were subjected to a detailed series of comparison. Results presented here have been limited mostly to summer and annual data, since most major changes in frequencies took place in summer.

\section{Evaluation techniques}

As shown by Changnon and Schickedanz (1971), the final proof and scientific acceptance of inadvertent weather modification cannot and should not rest entirely upon standard statistical testing methods. Even before climatological analyses can be performed properly to identify urban-induced precipitation effects, an hypothesis on how the effect may be produced and where it should occur should be evolved (as described for St. Louis in previous sections). After a thorough climatological-statistical study is performed, any apparent urban effect should be verified further and physical causes investigated through field experiments designed to measure pertinent meteorological parameters controlling the cloud development and rainproducing processes. As mentioned earlier, such a program was initiated at St. Louis in summer 1971 as a result of findings in the climatological study.

In this paper we are concerned only with the initial phase of the urban research at St. Louis; that is, the climatological study which identified the existence, general magnitude, and approximate location of an apparent urban-induced effect on the regional precipitation. In so doing, we decided in the planning stages of this research that analyses would be performed on all precipitation factors for which climatological data were available and which, conceivably, could be affected by urban environmental factors. The combined weight of the evidence evolving from these varied analyses would then dictate our conclusions. It was agreed that considerable reliance would be placed upon spatial pattern analyses to determine the existence (or absence) of an urban effect and to alleviate interpretation problems that could arise from occasional non-representative data that might be undetected by the data evaluation procedures discussed in the next section. 
It was further decided that standard statistical testing would be applied in those analyses where it was considered applicable and useful as an evaluation guide. However, complete reliance on statistical testing was not considered acceptable. For example, randomization techniques cannot be applied properly in some urban precipitation analyses since the urban effect is uncontrollable, and the factors which cause the effect are either unknown or the degree to which they are present is unknown at the start of an urban climatology study. This eliminates the usual treatment vs non-treatment comparisons that are useful in planned weather modification where the non-treatment data serve as the control.

Another statistical problem encountered in the St. Louis study and at all eight cities under investigation by the authors is the lack of sufficiently long records and adequate station density to determine satisfactorily the statistical significance of apparent abnormalities in the precipitation distribution in urban areas. An urban effect, if present, would have existed to some degree over the entire period of record at most urban-area stations; thus, there is no proper base or norm for evaluating time changes.

Finally, there is considerable question on the part of the authors as to the strict applicability of standard statistical tests in evaluating the significance of small precipitation abnormalities in a regional pattern which may be very real but tests as statistically insignificant. It is doubtful that rain events can be treated as a series of random numbers, since these events are certainly not truly random. Consequently, the same care should be exercised in interpreting statistical test results as in evaluating the implications of all other types of analyses employed in studies such as described here. The reader is referred to the paper by Changnon and Schickedanz (1971) for a more complete discussion of statistical problems and applications in urban-effect studies.

\section{Data used}

The primary source of data was the climatological records of precipitation published by the Environmental Data Service of NOAA (formerly U. S. Weather Bureau) for Missouri and Illinois. These data were supplemented by excellent precipitation records from five stations downwind of St. Louis operated since 1941 by the East Side Levee District of the U. S. Army Corps of Engineers. Daily weather maps published by the National Weather Service were used in analyses of synoptic weather conditions on urban effects. Locations of precipitation stations used in the study are shown in Fig. 1. In the precipitation analyses, major emphasis was placed upon the period starting in 1941, since the density of reporting stations prior to that was inadequate for many of the analyses.

A major problem in the urban study was to evaluate the reliability of available precipitation records in the study area. As part of this evaluation, a visit was made to all stations in the hypothesized Major and Minor Effect Areas of Fig. 1 to inspect raingage exposures and to evaluate the capabilities and interests of the paid and cooperative observers in weather observations. Within the two effect areas, we found no evidence to doubt the veracity of the observational data. Furthermore, we were particularly fortunate that the paid observers of the East Side Levee District were very capable, stations had remained in the same locations since 1941, and all observers had a long period of experience extending throughout all or most of the 1941-68 period. This was especially important, since as will be seen later, a downwind peak in seasonal rainfall occurs in the vicinity of two of these stations (CEN, EDG).

Another effort undertaken to minimize observational errors involved review of station histories for all precipitation stations with the Illinois-Missouri study area. These were obtained from the Illinois State Climatologist. As the monthly and seasonal analyses were completed, changes in observer and/or location of each station were examined to ascertain any corresponding change in the precipitation distribution at that station or with respect to surrounding stations. If any questionable change was discerned, all or part of the record was eliminated from the various analyses. Otherwise, the record was accepted since elimination of all stations with observer and/or site changes would have made special pattern analyses impossible.

The reader will note that the periods of record used in various analyses in this paper are not always consistent. Thus, analyses of thunder and hail days are confined primarily to the $1938-68$ period (or portions thereof), whereas seasonal rainfall analyses are based on data for the 1941-68 period. This difference arises because the length of reliable records of various precipitation events is not consistent. It was decided that all reliable records would be used for each analysis, rather than discard useful data in some cases to keep all analyses on the same time basis. Thus, data from both first-order and cooperative substations for the 1901-68 period were used in the thunder-hail studies, and acceptability of substation records for these events determined from an evaluation technique developed by Changnon $(1957,1966)$. The result of the substation evaluation is shown in Fig. 1.

\section{Urban effects on monthly and seasonal precipitation}

Spatial analyses showed a persistent, localized high in the summer (June-August) rainfall in the Major Effect Area of Fig. 1 throughout the 1941-68 period. This is illustrated in Fig. 2 for the last 10 years (195968) and for the entire sampling period (1941-68). Major features are the same, although the orientation of the downwind high changed somewhat as a result of a de- 


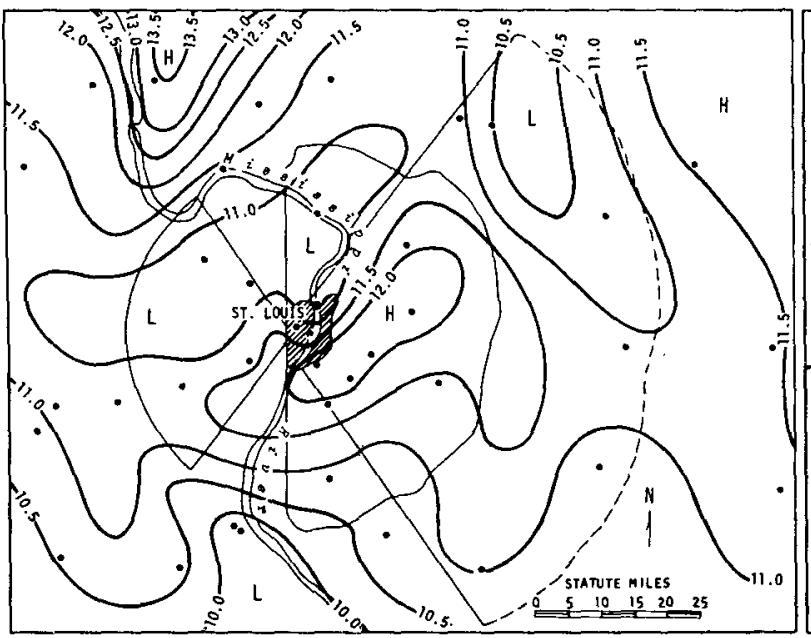

a.

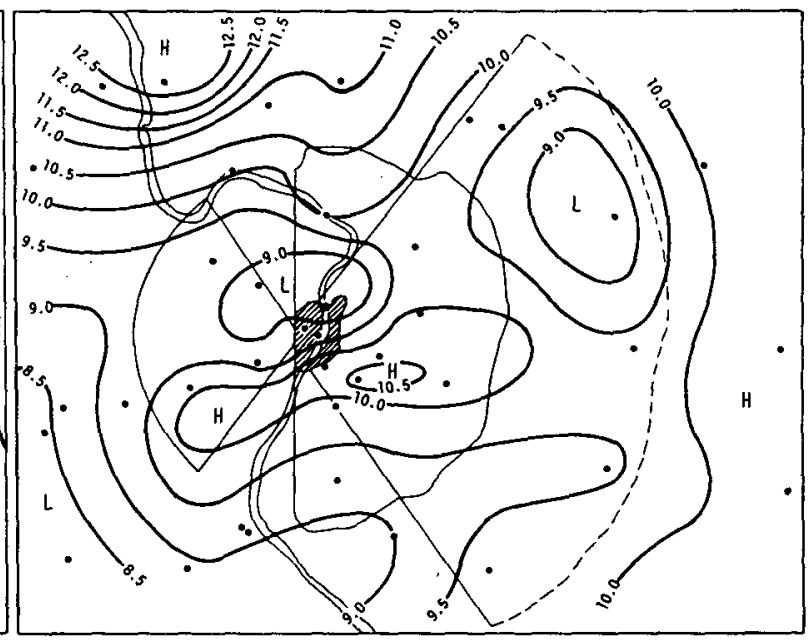

b.

FIG. 2. Summer rainfall patterns during selected periods: 1941-68, a., 1959-68, b.

crease in summer rainfall during recent years in the Edwardsville (EDV) region compared with that at Centreville (CEN). From a visit to Hardin (HAR), it was concluded that the single-station high at that location (NW of St. Louis beyond the control and effect areas) has resulted from an exposure problem (tree splash in very sheltered location). Note that the high in the Major Effect Area, however, is supported by several stations, and no exposure or observational deficiencies were found at these stations.

In winter (January-February) evidence was found of a minor localized high in the Edgement (EDG) region of the Major Effect Area, but identification was complicated by the presence of a winter climatic ridge extending northwestward through southern Illinois in the direction of St. Louis. Spring (March-May) was similar to summer with a persistent high in the Major Effect Area near CEN. The fall (September-November) average precipitation maximized in the Upwind Control Area southwest of the city, but there was slight evidence of a secondary high near EDV in the Major Effect Area.

Although the presence of a localized anomaly downwind of St. Louis can be identified by the seasonal analyses described above, it cannot be determined whether this anomaly has resulted from urban-induced effects, topographic influences (Ozarks), or a combination of these two factors. The next step in the analytical process was to construct seasonal precipitation ratio maps, such as those illustrated for summer rainfall in Fig. 3. Fig. 3 indicates that the CEN high of Fig. 2 has been intensifying with progressing time with respect to the average city rainfall; that is, the rural/urban ratio has increased in the more recent years (1959-68) compared with the long-term average (1941-68). Examination of Figs. 2 and 3 indicates that summer rainfall has decreased with progressing time throughout the sampling region, and that the ratio increase at CEN is the result of a lesser rate of decrease than experienced in the city.

Table 1 shows additional comparisons of summer rainfall ratios between various combinations in the urban effect and control (no-effect) areas for the 194168 sampling period and for the last 10 years of that period. CEN, located at the center of the downwind high, experienced $9 \%$ more rainfall than the 2-station city average (STL-UNI), 10\% more than the Upwind Control average, and 13\% more than the Downwind Control average during the 1941-68 period. These percentages increased substantially during the last 10 years of the sampling period, 1959-68. This is considered evidence in support of an urban-induced rainfall increase, since the local anomaly has intensified with progressing time in the CEN area, and topographicinduced variations or natural climatic differences would not be expected to change with time. Comparison of the average rainfall in the Major Effect Area with that in the two control areas indicates $8-10 \%$ greater rainfall in the urban-effect area, but this difference remains

TABLE 1. Comparison of summer rainfall ratios in urban effect and control areas.

\begin{tabular}{lcc} 
Ratio areas & 1.09 & 1.20 \\
Ratio in given \\
sampling period \\
CEN/City & $1941-68$ & $1959-68$ \\
CEN/Upwind Control & 1.10 & 1.16 \\
Major Effect/Upwind Control & 1.09 & 1.09 \\
Major Effect/Downwind Control & 1.10 & 1.08 \\
Minor Effect/Upwind Control & 1.00 & 1.01 \\
Minor Effect/Downwind Control & 1.02 & 1.00 \\
Major Effect/Minor Effect & 1.08 & 1.09 \\
Upwind Control/Downwind Control & 1.02 & 0.99 \\
\hline
\end{tabular}




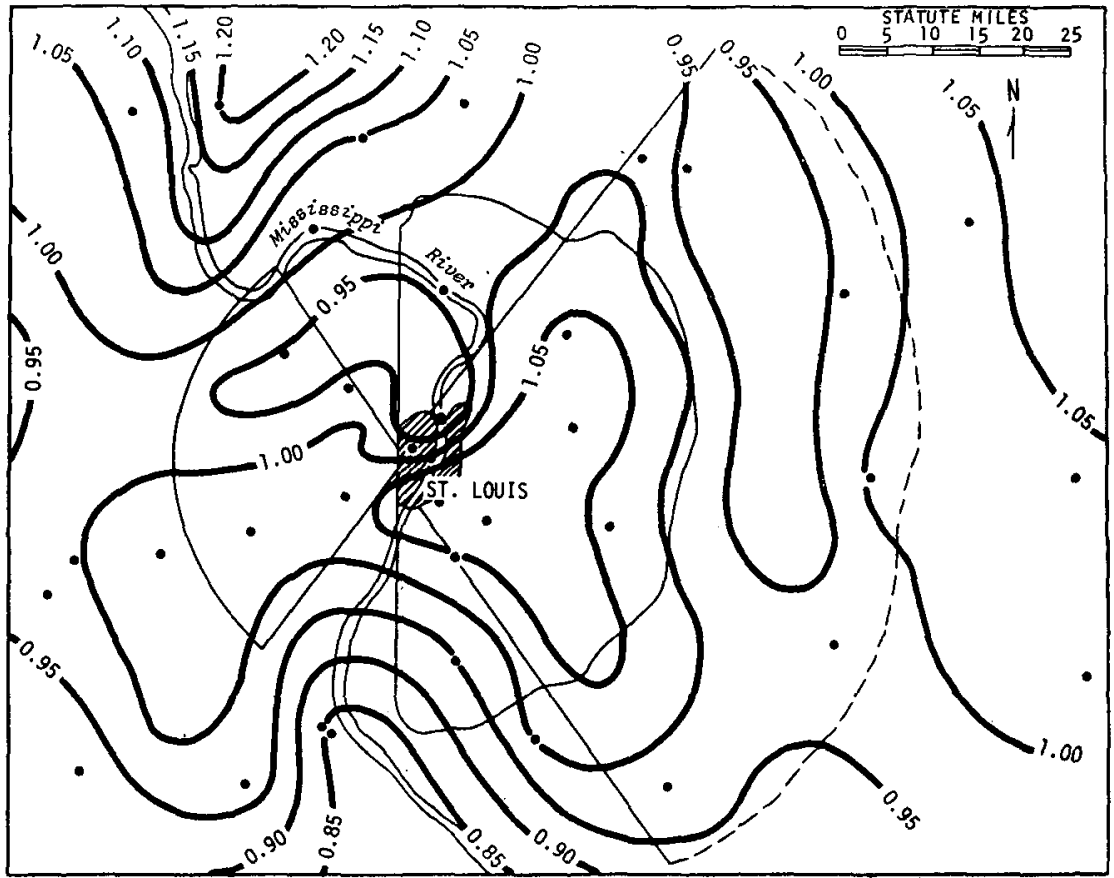

a.

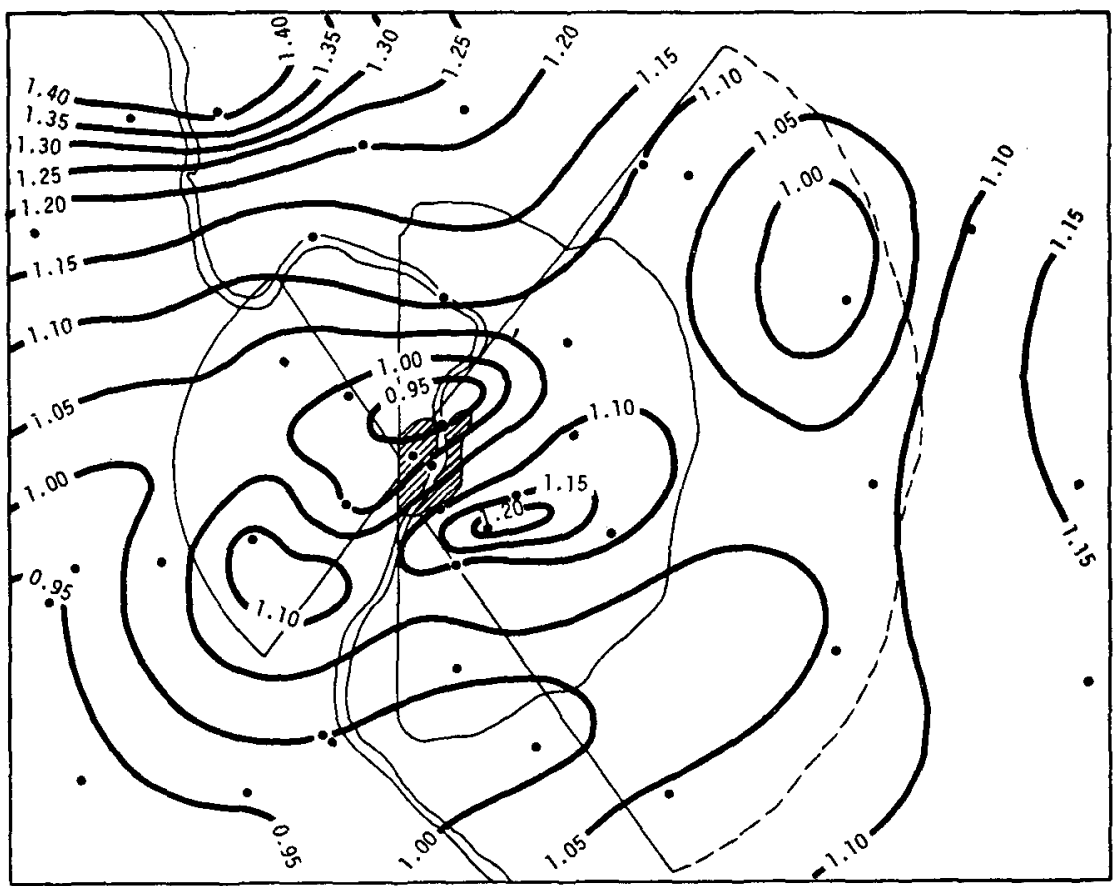

b.

FIG. 3. Summer rainfall ratio patterns for selected periods: 1941-68, a., 1959-68, b.

nearly constant with time. Thus, only in the CEN area is there evidence of continued intensification of the local rainfall effect.

The ratios between the Minor Effect Area and the two control areas in Table 1 show little evidence of a local effect on summer rainfall. Also, there is only a very small difference in average summer rainfall between the Upwind and Downwind Control Areas. This lack of a significant climatic gradient of summer rainfall between the two control regions provides additional 
evidence that the heavier rainfall in the Major Effect Area, located between the two controls, is related to local effects, either urban or topographic.

As a guide in evaluating the significance of the differences in summer rainfall between the control and hypothesized effect areas, $t$-tests were made between various combinations of areas for the 1941-68 period. Results are summarized in Table 2 in which the two-tail probability is shown for the various comparisons. Thus, data for the 28-year sampling period indicate a relatively high significance for the differences between the Major Effect Area and each of the two control areas and between the central city and Major Effect Area. However, differences between the hypothesized Minor Effect Area and the two control areas are not significant. Overall, the $t$-tests provide support for an urban-induced effect in the Major Effect Area, but not in the hypothesized Minor Effect Area, as indicated by the space-time patterns discussed above.

Analyses of monthly spatial patterns were made in an effort to delineate further the downwind effect. This produced some evidence of a localized effect during May, June, July and August in the Major Effect Area. Any effect present in other months was subject to sufficient interference from the normal climatic pattern to render its identity questionable. As indicated in the seasonal analyses, a natural ridge in the climatic pattern extends into the urban area from the southeast. This pattern starts in late August, and except for October, continues throughout the fall and winter into April.

Table 3, calculated from 1949-68 data, provides some indication of monthly localized effects in the warm season. The average monthly precipitation ratio in the Major Effect Area is greater than in the two control areas during May, June, July and August. However, the evidence is weak in August when the shift in climatic pattern confuses the issue. In July, the urban area and the Major Effect Area have nearly equal monthly means, as indicated by the rainfall ratio of 0.99 and this suggests that an urban effect (if present) may be maximizing both within and downwind of the city at that time. The typical spatial pattern of rainfall ratios for July (Fig. 4) indicates a localized increase centered near EDG.

Evidence of an urban-induced increase in summer rainfall was provided by time-trend analyses. Time trends of seasonal precipitation showed a general decrease throughout the St. Louis region during $1941-68$, but this trend was less pronounced in the
TABLE 2. Significance testing of 1941-68 summer rainfall differences between effect and control areas.

\begin{tabular}{lc} 
Comparison area & Two-tail probability \\
\hline Major Effect vs Upwind Control & 0.016 \\
Major Effect vs Downwind Control & 0.017 \\
Major Effect vs City & 0.012 \\
Minor Effect vs Upwind Control & $\mathrm{N} / \mathrm{S}^{*}$ \\
Minor Effect vs Downwind Control & 0.65 \\
\hline
\end{tabular}

* Not significant, outside table probability values.

region of the downwind high (Fig. 2). This is shown in Fig. 5 for CEN, located approximately $10 \mathrm{mi} \mathrm{SE}$ of the central city and at the center of the summer downwind high. Fig. 5 shows individual 5-year moving averages of the precipitation ratio, upon which is superimposed the time-trend regression line for the 1941-68 period.

A correlation coefficient of 0.89 and a standard error of 0.04 were obtained for the regression. Obviousiy, there has been a significant increase in summer rainfall at $\mathrm{CEN}$ relative to the urban area. This trend was most pronounced in the last 15 years of the sampling period, 1954-68. If urban-induced, this observed trend would be expected with gradual expansion of the urbanindustrial complex; if topographically related, the trend should not occur.

Evidence of the persistence of the summer downwind high is also shown in Fig. 5. During the last 15 years, every 5-year moving average of the rainfall ratio at CEN exceeded 1.05. Table 4 provides further verification of this persistence as shown by the percent of the 2 - and 5-year moving average of summer rainfall ratio that exceeded 1.00, 1.05 and 1.10 at each station in the Major Effect Area during 1954-68. From this analysis it is concluded that the downwind high is a persistent occurrence, not a statistical accident resulting from a few years of exceptionally heavy rainfall in the downwind region.

Evidence of a possible urban-induced winter effect centered in the CEN-EDG region was also found by time-trend analyses using ratios of average winter precipitation at CEN and EDG to averages for 1) an Upwind Control combination (APT-WG), 2) a Downwind Control pair (NHV-SPT), located near the axis of the long-term climatic high, and 3 ) the city combination (STL-UNI). Results are summarized in Table 5. All combinations indicate an increasing trend in the CEN-EDG region. Thus, winter precipitation has not

TABLE 3. Monthly mean precipitation ratios in Major Effect,

Upwind Control, and Downwind Control Areas, 1949-68.

\begin{tabular}{|c|c|c|c|c|c|c|c|c|c|c|c|c|}
\hline \multirow[b]{2}{*}{ Area } & \multicolumn{12}{|c|}{ Average ratios (given area to city) } \\
\hline & Jan & Feb & Mar & Apr & May & Jun & Jul & Aug & Sep & Oct & Nov & Dec \\
\hline Major Effect & 1.05 & 1.01 & 1.10 & 1.10 & 1.11 & 1.11 & 0.99 & 1.16 & 1.12 & 0.96 & 1.08 & 1.06 \\
\hline Upwind Control & 0.95 & 1.02 & 1.03 & 1.04 & 1.05 & 1.07 & 0.96 & 0.95 & 1.05 & 0.98 & 1.04 & 0.95 \\
\hline Downwind Control & 1.08 & 1.07 & 1.13 & 1.13 & 1.03 & 1.01 & 0.84 & 1.15 & 1.12 & 0.89 & 1.12 & 1.18 \\
\hline
\end{tabular}






FIg. 4. Average July rainfall ratios, 1949-68.

only been increasing in the Major Effect Area with respect to the city, but with respect to both control areas.

\section{Separation of natural and urban-related rainfall patterns}

Two techniques were used in an effort to separate the components of the downwind high (Fig. 2) resulting from urban-induced rainfall and that resulting from natural climatic variations. In the first analysis, data in the two control areas and at stations surrounding the control areas (Fig. 1) were plotted for several sampling periods. Isohyets were drawn through these data, and the resulting isohyetal patterns were considered to represent the natural distribution of summer rainfall with no urban effect. The rainfall pattern in the noeffect areas was used to interpolate or extend the analysis through the two effect areas. Pattern configura-

TABle 4. Percent of 2- and 5- year moving averages of rainfall ratios in the Major Effect Area that were equalled or exceeded during 1954-68.

\begin{tabular}{lcccccc}
\hline & \multicolumn{3}{c}{ Percent of cases for given ratio and period } \\
Major & \multicolumn{2}{c}{1.00} & \multicolumn{2}{c}{ 1.05 } & \multicolumn{2}{c}{ 1.10 } \\
Effect & 2-year & 5-year & 2-year & 5-year & 2-year & 5-year \\
station & 2-y & 2- & & & \\
\hline CEN & 86 & 100 & 86 & 100 & 71 & 82 \\
EDG & 86 & 100 & 79 & 100 & 71 & 91 \\
BLV & 86 & 100 & 86 & 91 & 57 & 73 \\
MIL & 79 & 100 & 64 & 91 & 50 & 45 \\
COL & 93 & 100 & 71 & 100 & 50 & 73 \\
EST & 79 & 100 & 64 & 91 & 57 & 45 \\
EDV & 57 & 82 & 57 & 45 & 57 & 27 \\
\hline
\end{tabular}

tions and rainfall gradients established in the surrounding area were taken into consideration. The interpolated rainfall pattern in the effect areas was then assumed to represent the rainfall that would have occurred in the absence of any urban effect. Next, the station values obtained from the isohyetal interpolation were subtracted from the actual observed values and the difference assigned to urban effect. This procedure was accomplished for four sampling periods which included $1941-68,1949-68,1959-68$ and $1964-68$. These various sampling periods were used to evaluate the consistency of the analytical method and to investigate possible changes in location and/or intensity of the suspected urban effect with progressing time.

In the second separation analysis, a mathematical surface was fitted to the data outside of the two effect areas, and this surface was then extended through the two effect areas to provide estimates of the distribution of summer rainfall in the Major Effect and Minor Effect Areas with removal of the localized effect. This is an adaptation of a method proposed by Wadsworth (1951) for evaluating seeding-induced rainfall increases in target areas during weather modification experiments.

TABle 5. Trend of 5-year moving ratios of winter precipitation, 1941-68.

\begin{tabular}{cccc}
\hline Ratio combinations & Ratio & Trend & $\begin{array}{c}\text { Correlation } \\
\text { coefficient }\end{array}$ \\
\hline CEN-EDG/STL-UNI & 1.06 & +0.013 & +0.71 \\
CEN-EDG/APT-WG & 1.07 & +0.011 & +0.80 \\
CEN-EDG/NHV-SPT & 0.89 & +0.007 & +0.56
\end{tabular}


TABLE 6. Estimates of urban effects on areal averages, based on curve-fitting and isohyetal techniques applied to summer rainfall.

\begin{tabular}{|c|c|c|c|c|c|c|c|c|c|}
\hline \multirow[b]{3}{*}{ Area } & \multicolumn{9}{|c|}{ Urban-induced difference $(\%)$ for given condition } \\
\hline & & $1941-68$ & & & $1959-68$ & & & 1964-68 & \\
\hline & $\begin{array}{l}\text { Curve } \\
\text { fitting }\end{array}$ & $\begin{array}{c}\text { Iso- } \\
\text { hyetal }\end{array}$ & Average & $\begin{array}{l}\text { Curve } \\
\text { fitting }\end{array}$ & $\begin{array}{c}\text { Iso- } \\
\text { hyetal }\end{array}$ & Average & $\begin{array}{l}\text { Curve } \\
\text { fitting }\end{array}$ & $\begin{array}{c}\text { Iso- } \\
\text { hyetal }\end{array}$ & Average \\
\hline Major Effect & +11 & +9 & +10 & +10 & +10 & +10 & +14 & +12 & +13 \\
\hline Minor Effect & 0 & +1 & +1 & +3 & +2 & +2 & +3 & +6 & +5 \\
\hline City only & +1 & +1 & +1 & -2 & $-\overline{1}$ & $-\overline{1}$ & +3 & +7 & +5 \\
\hline Major and Minor & +6 & +6 & +6 & +7 & +7 & +7 & +9 & +9 & +9 \\
\hline
\end{tabular}

In principal, it is similar to the isohyetal extension method described above, but removes subjectivity from the rainfall interpolations.

St. Louis summer rainfall at the sampling points within the two effect areas were obtained from a 17 term equation which resulted from the decision to expand terms until a multiple correlation coefficient that explained $75 \%$ of the variance $(0.87)$ was obtained for all sampling periods. The lengthy expansion was considered appropriate since there was no intention of using the empirical equation for future prediction purposes.

Table 6 shows the average percentage changes resulting from estimated urban effects on summer rainfall in the two effect areas for the 28-year period and during the last 5 and 10 years of the sampling period. Results from both separation techniques are shown along with a combined average, and they are remarkably similar. For the 28-year period, the estimates indicate an increase of approximately $10 \%$ in rainfall in the Major Effect Area from the urban effect, but only a $1 \%$ increase in the Minor Effect Area and within the city (STL-UNI). No major changes in the estimated urban effect are indicated in the 1959-68 averages, but an increased effect is indicated during the 1964-68 period.

Table 7 shows results of significance testing of the differences between the actual and predicted means of summer rainfall in the Major and Minor Effect Areas combined. The predicted mean represents the rainfall attributed to the natural climatic distribution, based upon the plane-fitting results, and the differences represent the estimated urban-induced increases in the hypothesized effect areas. A $t$-test of the differences was computed for four sampling periods $(28,20,10$ and 5 years) to aid in evaluating the temporal stability of

TABLE 7. Significance testing of estimated urban-induced increase in summer rainfall in Major and Minor Effect Areas.

Sampling period

1941-68 1949-68 1959-68 1964-68

\begin{tabular}{lrrrr}
\hline Predicted climatic & 10.74 & 10.68 & 9.06 & 8.72 \\
$\quad$ mean (inches) & 11.49 & $\mathbf{1 1 . 0 7}$ & 9.78 & 9.54 \\
Actual mean (inches) & 0.76 & 0.31 & 0.72 & 0.82 \\
Estimated urban-induced & & & & \\
difference (inches) & $<0.01$ & 0.04 & $<0.01$ & $<0.01$ \\
\hline
\end{tabular}

the estimated urban effect. The one-tail probability presented in Table 7 show a very high degree of significance $(<0.01)$ in all except 1949-68 when it was still relatively high with a probability of only 0.04 that the mean difference was due to chance.

Table 8 provides a comparison of estimated urbaninduced effects at individual stations in the Major Effect Area, based on averages of the two separation techniques. There is evidence of a shift in the location of the downwind maximum with progressing time. This urbaninduced maximum has shifted from the EDV-COL area to the CEN area in recent years, as indicated also in the total rainfall patterns of Fig. 2. Fig. 6 shows the rainfall pattern for 1941-68 derived from averaging the curve fitting and the isohyetal interpolations in the two hypothesized urban-effect areas. Comparison of Fig. 6 with Fig. 2a illustrates the change brought about by superimposing the estimated urban effect on the natural summer rainfall pattern in the Major Effect and Minor Effect Areas.

Of primary interest is a comparison of the rainfall ratio maps of Fig. 3 with Table 8 . The 1941-68 ratio map shows that the summer rainfall at EDV averaged $6 \%$ more than in the city. However, the separation analysis of Table 8 indicates that the urban-induced effect at EDV was considerably greater $(+15 \%)$ when the urban effects are separated from the natural climatic distribution. In general, Table 8 shows higher percentage increases from the estimated urban effect in the Major Effect Area during the 1941-68 period than



Fig. 5. Time trend of CEN summer rainfall ratios. 


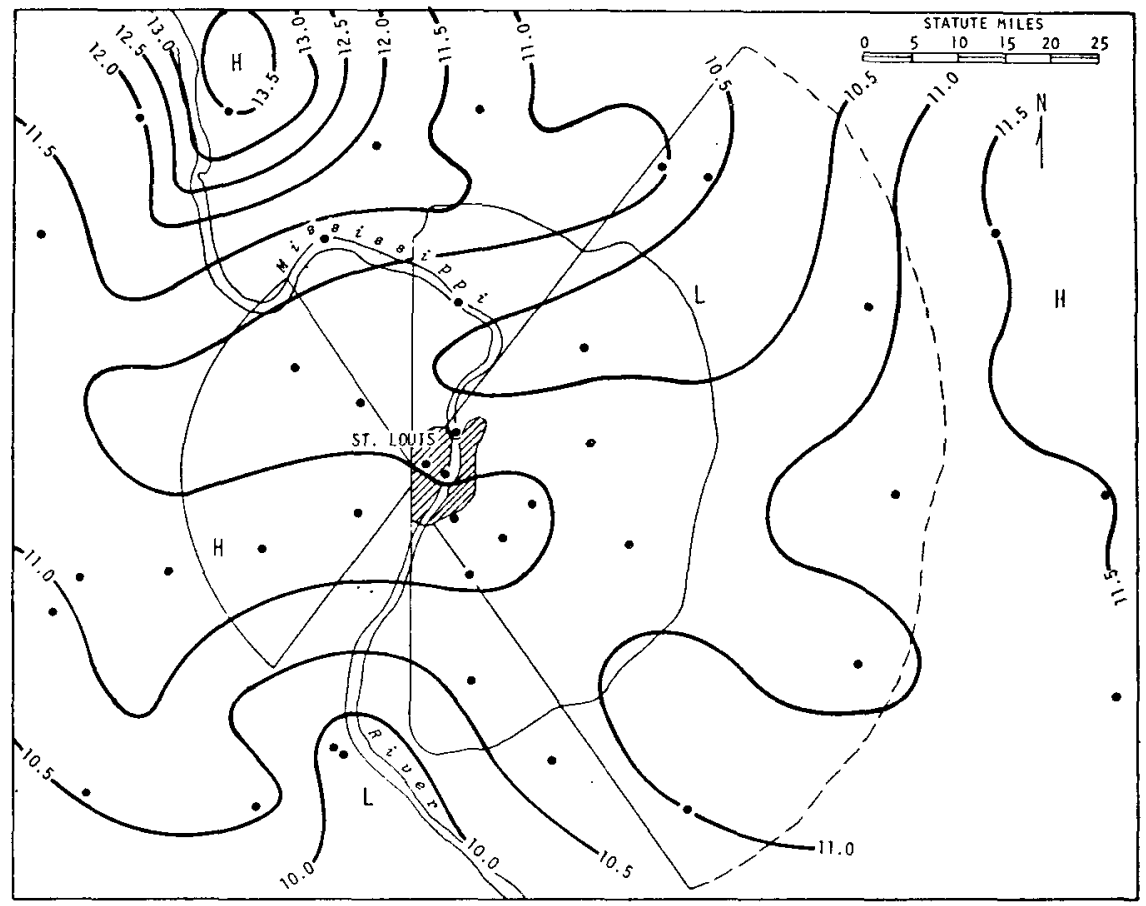

FIG. 6. Summer rainfall pattern with urban effect removed, 1941-68.

indicated by the urban/rural ratios of Fig. 3. Apparent intensification of the urban effect in the Major Effect Area during 1964-68 was confined mostly to the CEN area, although some increase is also indicated northeast and west of CEN in the EDG and EST regions. The major increase at CEN in recent years was also very evident in the time trend analyses (Fig. 5) discussed earlier.

\section{Wet-dry period analyses}

Analyses were performed to determine whether significant differences might occur in the nature of the observed local effect during relatively wet and dry periods. For this study, summer rainfall totals during the 1941-68 period were divided according to the 9 driest and 9 wettest summers with the remaining 10 summers classified as moderate. The classifications were based on averages of summer rainfall at all stations in the Major Effect and Minor Effect Areas of Fig. 1.

TABLE 8. Estimates of urban effects on point rainfall in Major Effect Area, based on averages obtained from curve fitting and isohyetal techniques applied to summer rainfall.

\begin{tabular}{cccc}
\hline & \multicolumn{3}{c}{ Urban-induced difference (\%) } \\
\hline Station & $1941-68$ & $1959-68$ & $1964-68$ \\
\hline EDV & +15 & +10 & +7 \\
COL & +14 & +11 & +13 \\
EDG & +10 & +11 & +14 \\
BLV & +6 & +10 & +8 \\
CEN & +11 & +17 & +28 \\
EST & +11 & +11 & +17 \\
MIL & +6 & +4 & +5 \\
\hline
\end{tabular}

Fig. 7 shows the spatial rainfall patterns for each of the three classifications. Comparison of Figs. $7 \mathrm{a}$ and $7 \mathrm{~b}$ shows that the wet-summer and moderate-summer patterns are strikingly similar to each other and to the average rain patterns of Fig. 2. This is an indication that if an urban effect exists, it is operating during both types of summers. However, the dry-summer pattern of Fig. 7c shows a pronounced departure from the wet and moderate distributions with the region of relatively heavy rainfall displaced to the north of the city and relatively light rainfall in the area of the downwind high in Figs. 2, 7a and 7b. The change in pattern characteristics in dry summers could result from 1) an insignificant urban effect in these summers, so that the downwind high is eliminated; 2) a negative urban effect on the rainfall process; or 3) shifts in the urban effect, perhaps due to changes in circulation, predominant storm types, or effectiveness of certain urban factors (heat island, nucleation potential, etc.).

Examination of precipitation ratios for the three classifications of Fig. 7 revealed that the average rural/urban ratios in the Major Effect Area during dry summers were equal to or greater than those in the wet and moderate summers, although all three ratio patterns were similar to those of actual rainfall in Fig. 7. The pronounced change between the wet-moderate pattern and dry summer pattern was, therefore, not the result of eliminating the basic urban-downwind relation, but rather of a distinct change in the relation between the urban rainfall and rainfall to the north and south of the city. 


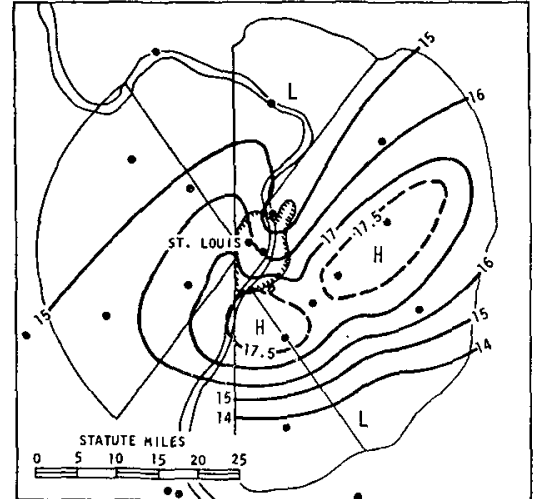

a.

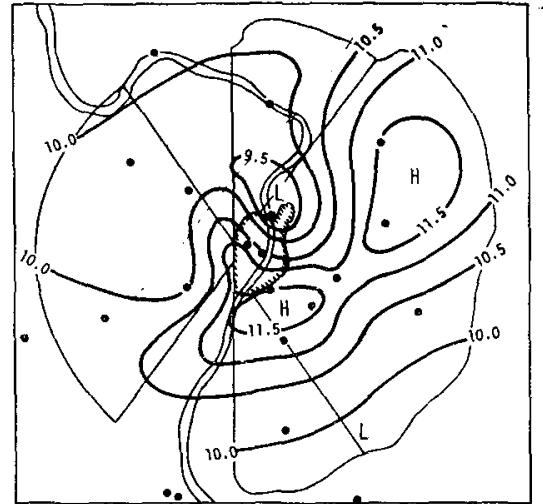

b.

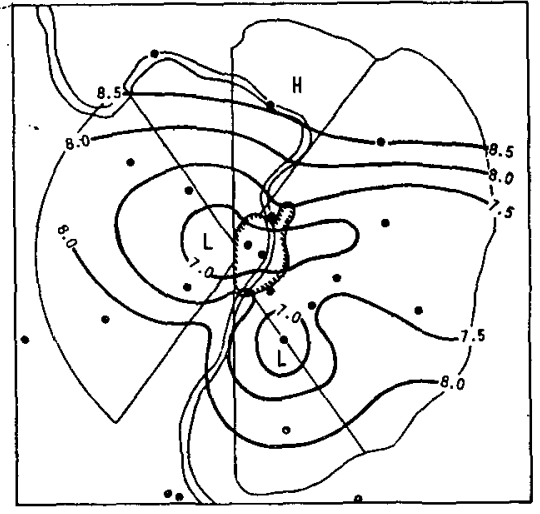

c.

FIG. 7. Isohyetal patterns of wet, a., moderate, b. and dry, c., summers, 1941-68.

Table 9 shows average ratios in various areas during wet and dry summers, along with the 1941-68 average for all years combined. The CEN-EDG average was computed to portray relations near the center of the normal downwind high rainfall zone (Fig. 2), and the EDV-ALT combination provides a measure of conditions north of the city where a pronounced change in the rural/urban ratio occurs between the wet-moderate and the dry summers (Fig. 7).

Table 9 shows that the average rainfall ratios are very similar in most areas during wet years and for the total 28-year sampling period. In all cases, the ratio increases from the wet-year sample to the dry-year sample, and this increase is pronounced in the two control areas and in the EDV-ALT area. A possible explanation for this change is that an urban effect is intensifying the natural rainfall within and downwind of the city in wet to moderate summers, but is suppressing the rainfall within and immediately downwind of the city in dry summers with maximum suppression within the urban area. If suppression were taking place during dry summers as suggested above, the ratios in the Major Effect Area would tend to increase somewhat. However, such an urban-downwind suppression would result in a shift of the isohyetal pattern shown in Fig. 7. Thus, the shift to higher rainfall amounts north and south of the city could be the result of their being outside an urban suppression zone in dry summers. The Upwind and Downwind Control Areas would be expected to have increased ratios in the dry summers, also, as shown in Table 9, because any urban suppression mechanism would not affect these areas either. Urban rainfall suppression during dry summers could be related to above-normal evaporation of rain between clouds and ground in the predominantly light rains over the excessively hot city (heat island) during such periods.

During wet and moderate summers, intensification of rainfall within the city would tend to suppress the ratios in the two control areas and increase it in the Major Effect Area where the intensification maximizes, assuming the normal climatic differences in summer rainfall between the three areas is insignificant. A possible explanation for the relatively low ratio in the Downwind Control Area in wet years is that maximization of an urban effect in the Major Effect Area resulted in a compensating decrease of rainfall downwind of the inadvertent rainfall modification due to dynamic reactions.

As an effort to obtain further information on the above hypothesis of wet-dry summer relations, an analysis was made of the percentage of the total 1941-68 summer rainfall occurring in the 9 wettest and 9 driest years at each station in the Major and Minor Effect Areas of Fig. 1. The purpose was to determine whether the city and Major Effect Area had a lower percentage of their 28-year total in the 9 driest summers than did the control areas. Conversely, in the 9 wettest summers, the city and Major Effect Area would be expected to receive a higher percentage of their 28-year totals than did the control areas.

Results summarized in Table 10 support the hypothesis that rainfall is intensified in wet years and suppressed in dry years in the urban area and Major Effect Area. When station averages in each area are combined, the lowest percentage in dry years occurs in the city, followed closely by the Major Effect Area, and substantially greater percentage values occur in the control areas. The opposite relationship occurs in wet summers, with maximum percentage in the Major Effect Area,

TABLE 9. Average rainfall ratios in wet and dry summers during 1941-68.

\begin{tabular}{lccc}
\hline & \multicolumn{3}{c}{ Average ratios to city } \\
Area & Wet & Dry & All \\
\multicolumn{1}{c|}{ years } & years & years \\
\hline Major Effect & 1.08 & 1.12 & 1.07 \\
Upwind Control & 0.97 & 1.17 & 0.98 \\
Downwind Control & 0.90 & 1.21 & 0.97 \\
CEN-EDG & 1.10 & 1.12 & 1.09 \\
EDV-ALT & 0.96 & 1.29 & 1.02 \\
\hline
\end{tabular}


TABLE 10. Percent of average summer rainfall based on nine wettest and nine driest years at each station during 1941-68.

\begin{tabular}{|c|c|c|}
\hline \multirow[b]{2}{*}{ Area } & \multicolumn{2}{|c|}{$\begin{array}{l}\text { Area average } \\
\text { percentage }\end{array}$} \\
\hline & Wet years & Dry years \\
\hline Major Effect & 149 & 59 \\
\hline Upwind Control & 142 & 63 \\
\hline Downwind Control & 139 & 65 \\
\hline City & 148 & 57 \\
\hline CEN-EDG & 149 & 58 \\
\hline EDV-ALT & 140 & 65 \\
\hline
\end{tabular}

followed closely by the city, and considerably lower values in the control areas.

Analyses were made to ascertain the consistency in location of centers of light and heavy summer rainfall in the Major and Minor Effect Areas. For this purpose a rank scoring was applied to all stations in these two areas except $\mathrm{GC}$ whose record was incomplete. In the station rankings, a score of 3 was allowed for first, 2 for second, and 1 for third. In the wet-summer and moderate-summer samples, rankings were accomplished for each year from heaviest to lightest rainfall totals. In the 9 dry summers, rankings were made from heavy to light rainfall and then from light to heavy amounts.

Results are summarized in Table 11 which shows total scores for each data stratification. In wet summers, no single station was outstandingly the wettest in the scoring system. Overall, the COL-EDG area appears to have been the most favored center of heavy rainfall in the wet summers, followed closely by the EST-MIL region. The urban area (STN-UNI) was rarely a high rainfall center. In moderate summers, the COL center was again present and the urban area remained low in scoring. In the two sets of scores for dry summers, the EDV-ALT region was consistently wet (wet-dry scores), whereas the urban area (STL-UNI) predominated in dryness (dry-wet scores). The EST-MIL region ranked second in scoring in both wet and dry summers. From this rank score analysis, it is concluded that centers of heavy and light rainfall have a tendency to persist from

TABLE 11. Rank scores for summer rainfall in wet, dry and moderate years during 1941-68.

\begin{tabular}{|c|c|c|c|c|}
\hline \multirow[b]{2}{*}{ Station } & \multirow[b]{2}{*}{$\begin{array}{c}\text { Wet } \\
\text { years }\end{array}$} & \multirow[b]{2}{*}{$\begin{array}{c}\text { Moderate } \\
\text { years }\end{array}$} & \multicolumn{2}{|c|}{ Dry years } \\
\hline & & & $\begin{array}{l}\text { Wet- } \\
\text { dry }\end{array}$ & $\begin{array}{l}\text { Dry- } \\
\text { wet }\end{array}$ \\
\hline EDV & 4 & 6 & 10 & 0 \\
\hline COL & 10 & 13 & 2 & 6 \\
\hline BLV & 2 & 3 & 3 & 3 \\
\hline EDG & 9 & 5 & 4 & 1 \\
\hline CEN & 5 & 8 & 5 & 2 \\
\hline MIL & 8 & 6 & 2 & 9 \\
\hline EST & 8 & 5 & 6 & 6 \\
\hline STL & 0 & 3 & 0 & 6 \\
\hline UNI & 2 & 3 & 1 & 13 \\
\hline ALT & 5 & 5 & 13 & 3 \\
\hline WAT & 1 & 3 & 8 & 5 \\
\hline
\end{tabular}

year to year in relatively small sectors within the Major Effect and Minor Effect Areas. Consequently, the pattern configurations of Fig. 7 are not the result of occasional very wet or dry summers.

\section{Rain-day and weekday-weekend relations}

An analysis was made of the 1951-68 rain-day frequencies in the St. Louis area to search for other evidence of an urban effect. This analysis was based on averaging point data for four stations in each of the various areas shown in Fig. 1. Regional averaging allows establishment of the "climatic background" (from control-area values), which might be due to orographic, longitudinal, and/or marine influences. This is a necessary prerequisite to numerical evaluation of the effectarea values. Furthermore, areal averages smooth out the impact of anomalous values from any single station that might have poor observations. Results are summarized in Table 12 for the warm or convective season (April-October) for four rain classes. Also shown is the percent of the total number of rain days occurring on weekdays (Monday-Friday).

In the warm season, the Major Effect Area had substantially more rain days than all other areas in the 0.25- and 0.5-inch classes, and more than the Downwind Control in the two lighter rain classes. Average values were then obtained for the combined Upwind Control and the Downwind Control to provide the climatic background values. It was found that in an average 5-year period the Major Effect Area had an added 10 days of measurable rainfall, 3 more of $\geqslant 0.1$ inch, 9 more of $\geqslant 0.25$ inch, and 6 more of $\geqslant 0.5$ inch. Thus, greater than normal climatic frequency of daily rainfall of all magnitudes occurred in the Major Effect Area, but the difference was most pronounced on days of moderateto-heavy rainfall.

Day-of-the-week differences in rain-day frequencies are important in establishing that the localized anomalies in rainfall are not due to some local physiographic or marine factors which would be a local effect operating every day (Lawrence, 1971). Inspection of the warm season weekday percentages in Table 12 reveals that the expected weekday frequency of $71 \%$ is exceeded in all rain classes in the Minor and Major Effect Areas. Also, the Major Effect percentages are all higher than the "climatic background" values of the upwind control and the downwind control regions. The binomial test was used to test the differences between the actual and expected frequencies of rain days during weekdays for each of the four areas. The binomial and optimal C-alpha tests were used to test for differences in the weekday frequencies between areas.

Results for the category of rain days in the $\geqslant 0.25$ inch class appear in Table 13. In addition, the smokehaze day frequencies at St. Louis, which can be used as an index of pollution and potential rain nuclei available, were tested for weekday differences. 
TABLE 12. Point rainfall frequencies during warm season in St. Louis area, 1951-68.

\begin{tabular}{|c|c|c|c|c|}
\hline & Upwind Control & Minor Effect & Major Effect & Downwind Control \\
\hline Number of days $\geqslant 0.01$ inch & 1030 & 1060 & 1035 & 966 \\
\hline Percent on weekdays & 71 & 72 & 72 & 71 \\
\hline Number of days $\geqslant 0.10$ inch & 731 & 716 & 730 & 713 \\
\hline Percent on weekdays & 72 & 72 & 73 & 72 \\
\hline Number of days $\geqslant 0.25$ inch & 469 & 492 & 506 & 480 \\
\hline Percent on weekdays & 70 & 73 & 75 & 71 \\
\hline Number of days $\geqslant 0.50$ inch & 272 & 277 & 294 & 272 \\
\hline Percent on weekdays & 70 & 72 & 72 & 71 \\
\hline
\end{tabular}

These results reveal that the Major Effect Area had significantly more rain days on weekdays than expected. The number of smoke-haze days on weekdays was also greater than expected. The probabilities that these differences were due to random chance were 0.02 and 0.01 , respectively. The binomial and the C-alpha test for differences between proportions in the various areas yielded probabilities of 0.05 for differences between the frequency of rain days in the Upwind Area and the Major Effect Area.

Huff and Changnon (1970) have presented the frequency of $\geqslant 0.25$ inch days for each day of the week in the four areas and the smoke-haze day frequency for each day of the week. Their results revealed: 1) that the Major Effect Area values on each of the five weekdays exceeded those of the two control areas and the Minor Effect Area, 2) there are no differences in the daily values of the four areas on either Saturday or Sunday, and 3) the smoke-haze days minimized on Sunday and maximized on Wednesday, Thursday and Friday.

Translation of the percentage values in Table 12 to actual numbers reveals that the average daily number of 0.25-inch days, based on 18-year totals in the Major Effect Area, was 75 rain occurrences on weekdays compared with 65 occurrences on a weekend day (Saturday or Sunday). Comparable values for the Upwind Control Area region are 66 (weekday) and 69 (weekend day), and in the Downwind Control are 68 and 68.

Similar weekday-weekend relations were found in the analyses of daily rainfall amounts. As shown in an earlier paper (Changnon et al., 1971), the Major Effect Area had a greater daily average rainfall during the warm season than either control area on all days, but the percentage difference was greatest on the weekdays. Thus, the Major Effect Area averaged $11 \%$ more rainfall on weekdays than the two control areas compared with $4 \%$ greater on weekends. The weekday-weekend differences in rain-day frequencies and rain quantity in the warm season are considered to be strong evidence that the downwind rainfall high in that season is urbaninduced rather than resulting from local topographic or marine effects.

Results of the cold season analysis (NovemberMarch) of rain days at St. Louis provided little evidence of urban industrial effects on precipitation during this season. Although a slight increase in the total number of rain days was found in the Major Effect Area, no significant difference was noted in the weekday-weekend comparisons. Frederick (1970) presented day-of-theweek rainfall for the St. Louis city station for a long period (1921-61), and these values indicated that the 50 -year average cool season rainfall on a weekend day (Saturday, Sunday) was 101.31 inches as compared to a weekday rainfall average of 111.01 inches, a $10 \%$ increase on weekdays.

\section{Frequency of heavy rainstorms}

If urban areas intensify or moderate naturally occurring heavy rainstorms, the frequency and magnitude of flood-producing storms will differ from those experienced in suburban and rural areas in the same rainfall climate, and would affect the design requirements for urban sewer systems. Since little (if any) information on this subject is available, a study was undertaken to determine if the St. Louis urban effect extended to extreme rainfall events.

In this study, comparisons were made of the frequency distribution of daily rainfall amounts equalling or exceeding 2.0, 2.5 and 3.0 inches in the urban and surrounding areas. These daily rainfalls are infrequent enough to be classified as heavy storms but supply sufficient samples over $10-20$ years to provide statistical significance. Data for the 1949-68 period were used, since the sampling density maximized in the St. Louis region during this period and provided the most reliable estimates of the heavy rainfall distribution.

Results of this study are summarized in Table 14, which shows the average number of occurrences in the Major Effect Area, the city, and the two control areas for each

TABLE 13. Values of $t$ for the binomial test of proportions of the differences between expected and actual frequencies of 0.25 -inch rain days on weekdays in St. Louis area, 1951-68.

\begin{tabular}{llcccc}
\hline & $\begin{array}{l}\text { Upwind } \\
\text { Control }\end{array}$ & $\begin{array}{c}\text { Minor } \\
\text { Effect }\end{array}$ & $\begin{array}{c}\text { Major } \\
\text { Effect }\end{array}$ & $\begin{array}{c}\text { Down- } \\
\text { wind } \\
\text { Control }\end{array}$ & $\begin{array}{c}\text { St. Louis } \\
\text { smoke- } \\
\text { haze } \\
\text { days }\end{array}$ \\
\hline $\begin{array}{l}t \text {-value } \\
\begin{array}{l}\text { 1-tail prob- } \\
\text { ability that } \\
\text { difference is } \\
\text { due to random } \\
\text { chance }\end{array}\end{array}-0.51$ & 0.56 & 2.02 & 0.02 & 3.64 \\
\hline
\end{tabular}




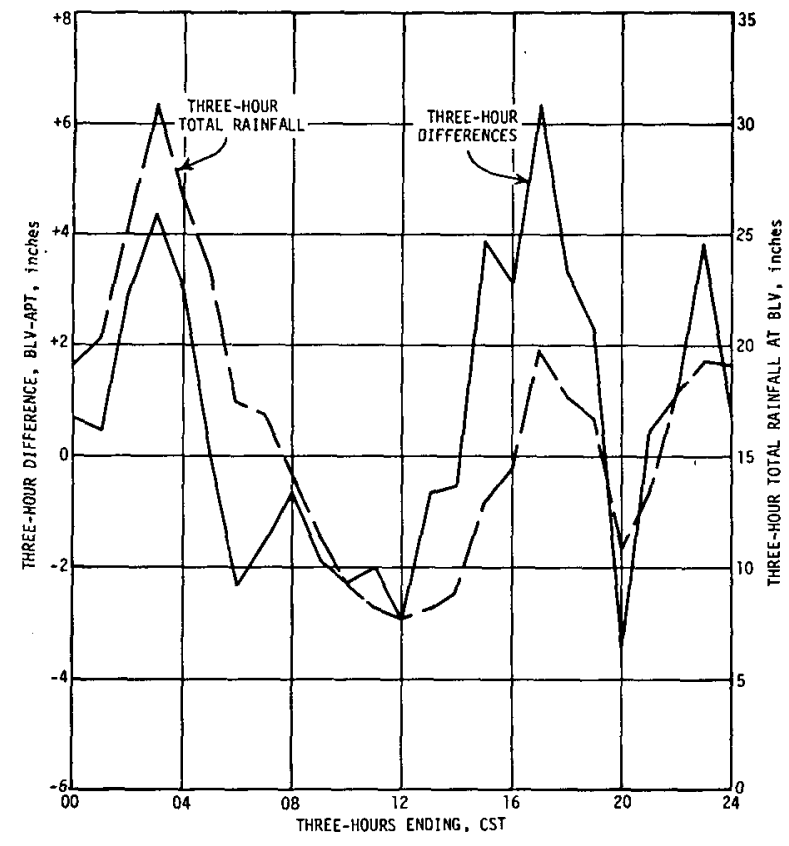

FIG. 8. BLV-APT comparisons in summer, 1952-65.

intensity class. The ratio of the number of occurrences in the Major Effect Area to the number in each of the other areas is also shown for each category. Table 14 provides evidence of an urban-induced increase in the frequency of heavy daily rainfalls of 2-3 inches, but also indicates very little urban effect associated with the extremely heavy rainstorms producing 3 inches or more. According to Hershfield (1961), a 24-hr rainfall of 3.5 inches will occur on the average of once in 2 years at St. Louis. On the basis of this statistic, the above results indicate that the urban effect should have little influence on design considerations for urban storm sewer systems and other hydraulic structures.

\section{Diurnal relations}

The diurnal rainfall distribution was studied to define more closely the time distribution characteristics of the apparent urban effect and to obtain additional evidence of its causes. Concurrent recording gage data available during the 1952-65 period at an Upwind Control station (APT), an urban station (STL), and a Major Effect station (BLV) were used. From these data, seasonal values of hourly rainfall and hourly rainfall differences between stations were calculated.
The most interesting feature in the diurnal distributions was in summer when the most pronounced urban effect, as indicated by the station rainfall differences between the upwind control and downwind major effect stations (BLV-APT), occurred during the period of maximum diurnal heating. This is illustrated in Fig. 8 which shows 3-hr moving averages of total rainfall at BLV and rainfall differences between BLV and APT. The total rainfall distribution agrees closely with the climatic average for this area (Huff, 1971).

Occurrence of the maximum positive difference in the 3 -hr period ending at 1700 CST suggests that stimulation of updrafts in clouds moving over the relatively hot city (heat island) augments the natural rainfall in the Major Effect Area. In Fig. 8, the rainfall at $\mathrm{APT}$ is greater than at BLV from early morning to early afternoon. This is most likely a climatic anomaly in view of Fig. 6 which shows that AP'T would receive more summer rainfall than BLV in the absence of an urban effect. This also could account for the early evening reversal in the difference trend of Fig. 8 (end of heat convection period). The secondary maximization of differences at night in Fig. 8 is indicative of a possible urban intensification of nocturnal thunderstorms that appear to be responsible for the early morning peak in the natural rainfall distribution (Huff, 1971).

Comparison of summer diurnal curves between BLV and STL also showed the afternoon and nocturnal maxima of differences (BLV-STL), as did the comparisons between STL and APT (STL-APT), although the differences were not as pronounced in the latter comparison. Examination of diurnal curves for winter provided little evidence of any urban effect. The BLVAPT differences were generally positive throughout the day, as expected from the regional climatic gradient. Spring showed the same general diurnal trends in rainfall differences as summer, but they were less pronounced. Fall trends were more similar to winter, and no substantial evidence of a diurnal difference in urban effects could be determined from the curves.

\section{Synoptic weather analyses}

Storm rainfall data for summer during the last 10 years of the sampling period (1959-68) were stratified according to basic synoptic weather types to search for differential urban effects. Since earlier analyses had indicated the downwind high resulted largely from intensification of moderate-to-heavy daily rainfalls,

TABLE 14. Frequency of heavy rainfalls, 1949-68.

\begin{tabular}{|c|c|c|c|c|c|c|}
\hline \multirow[b]{2}{*}{ Area } & \multicolumn{3}{|c|}{ Number of occurrences } & \multicolumn{3}{|c|}{ Ratio, Major Effect to other areas } \\
\hline & $\geqslant 2.0$ inch & $\geqslant 2.5$ inch & $\geqslant 3.0$ inch & $\geqslant 2.0$ inch & $\geqslant 2.5$ inch & $\geqslant 3.0$ inch \\
\hline Major Effect & 38 & 16 & 8 & & & \\
\hline Urban (STL-UNI) & 24 & 13 & 8 & 1.58 & 1.23 & 1.00 \\
\hline Upwind Control & 27 & 12 & 7 & 1.41 & 1.33 & 1.14 \\
\hline Downwind Control & 31 & 14 & $i$ & 1.23 & 1.14 & 1.14 \\
\hline
\end{tabular}




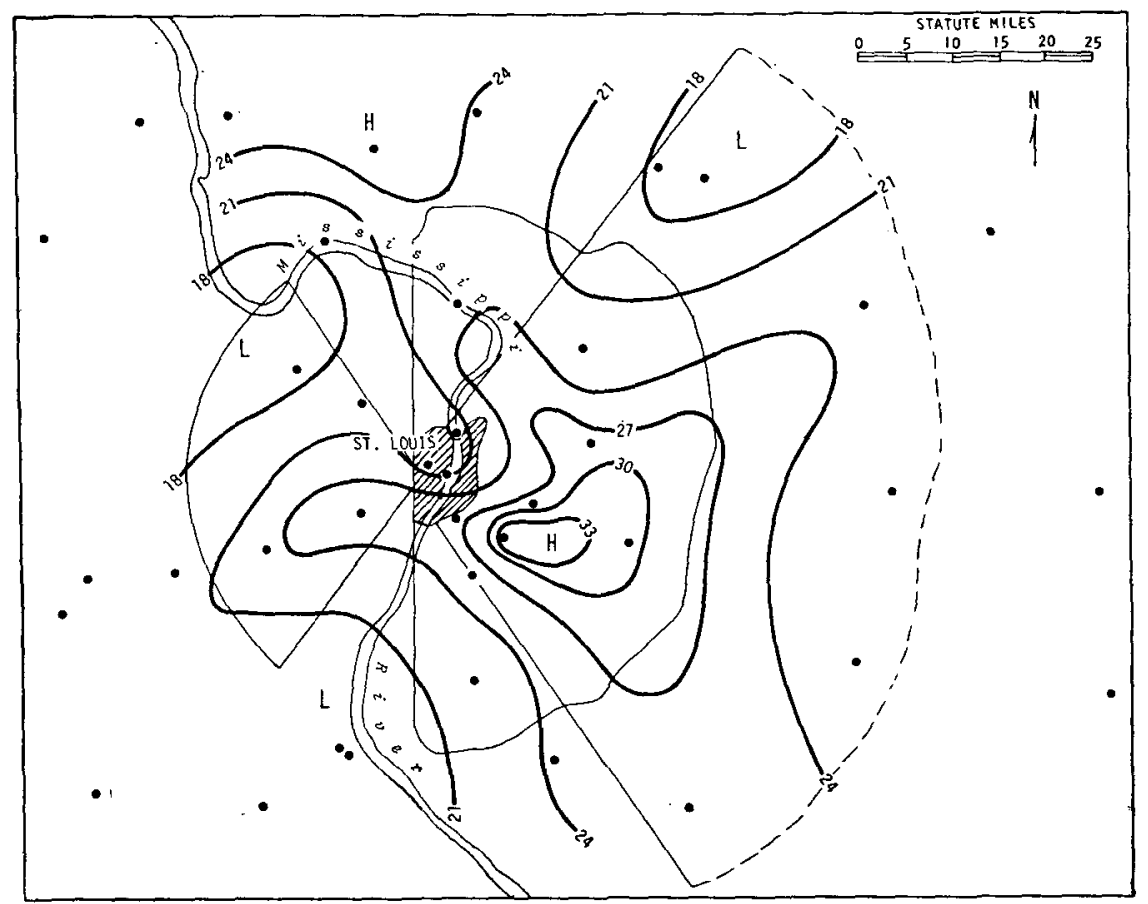

FIG. 9. Summer rainfall pattern in cold front storms, 1959-68.

this study was restricted to storms in which one or more stations in the four basic study areas (Fig. 1) recorded storm rainfall $\geqslant 0.25$ inch. This provided a sample of 213 storms during the 10-year period.

Results indicated that the summer downwind rainfall high resulted primarily from a strong tendency for rain from cold front storms to maximize in the Major Effect Area. A less pronounced trend was found also for squallline storms to maximize in the Major Effect Area, which is not surprising since the most common occurrence of these storms is in conjunction with advancing cold fronts. The pattern of average storm rainfall in the 51 cold front storms (Fig. 9) is similar to the average summer rainfall patterns (Fig. 2).

Further comparison of synoptic storm types and urban effects is presented in Table 15. In the upper part of this table the average rainfall in each of the four major storm types is shown for the two effect areas and the two control areas. Table 15 shows that nearly $50 \%$ of the total rainfall in all four areas resulted from cold fronts and squall lines, so that maximization of these storms in the Major Effect Area dictated the general pattern of summer rainfall to a large extent. However, the major dominance of the Major Effect Area was with cold fronts which produced average storm rainfall in this area that was $28 \%$ greater than in the Upwind and Downwind Control Areas. Although air mass storms were the most frequent type, storm amounts average only about one-half of the frontal storm averages. Reference to 1959-68 patterns for the various synoptic storm types showed the presence of a rainfall low in and/or upwind of the city with all kypes.

\section{Thunder-day and hail-day results}

Evaluation of available thunder and hail records showed that in addition to the two first-order stations (STL and APT), eight cooperative substations within $80 \mathrm{mi}$ of St. Louis had quality thunder data for 12 years or longer in the 1901-68 period. Eighteen cooperative substations had quality hail data for 17-year or longer periods, the locations being shown in Fig. 1.

\section{a. Thunder days}

Data for four stations nearest to St. Louis with the longest continuous records of thunder were analyzed

TABLE 15. Storm rainfall distribution by synoptic type in 213 storms with one or more stations $\geqslant 0.25$ inch during summer, $1959-68$

\begin{tabular}{llccc}
\multicolumn{1}{c}{ Area } & $\begin{array}{c}\text { Cold } \\
\text { fronts }\end{array}$ & $\begin{array}{c}\text { Squall } \\
\text { lines }\end{array}$ & $\begin{array}{c}\text { Static } \\
\text { fronts }\end{array}$ & $\begin{array}{c}\text { Air } \\
\text { mass }\end{array}$ \\
\hline & $\begin{array}{c}\text { Average storm rainfall (inches) for } \\
\text { given storm types }\end{array}$ \\
Major Effect & 0.55 & 0.51 & 0.49 & 0.26 \\
Minor Effect & 0.44 & 0.46 & 0.51 & 0.23 \\
Upwind Control & 0.42 & 0.48 & 0.54 & 0.21 \\
Downwind Control & 0.44 & 0.43 & 0.50 & 0.25 \\
Station median & 0.45 & 0.47 & 0.51 & 0.24 \\
Number of storms & 51 & 40 & 40 & 69 \\
& Percent of 213 -storm total rainfall \\
& \multicolumn{4}{c}{ for given storm types } \\
Major Effect & 30 & 22 & 21 & 19 \\
Minor Effect & 26 & 21 & 23 & 19 \\
Upwind Control & 25 & 22 & 25 & 17 \\
Downwind Control & 27 & 20 & 24 & 19 \\
\hline
\end{tabular}




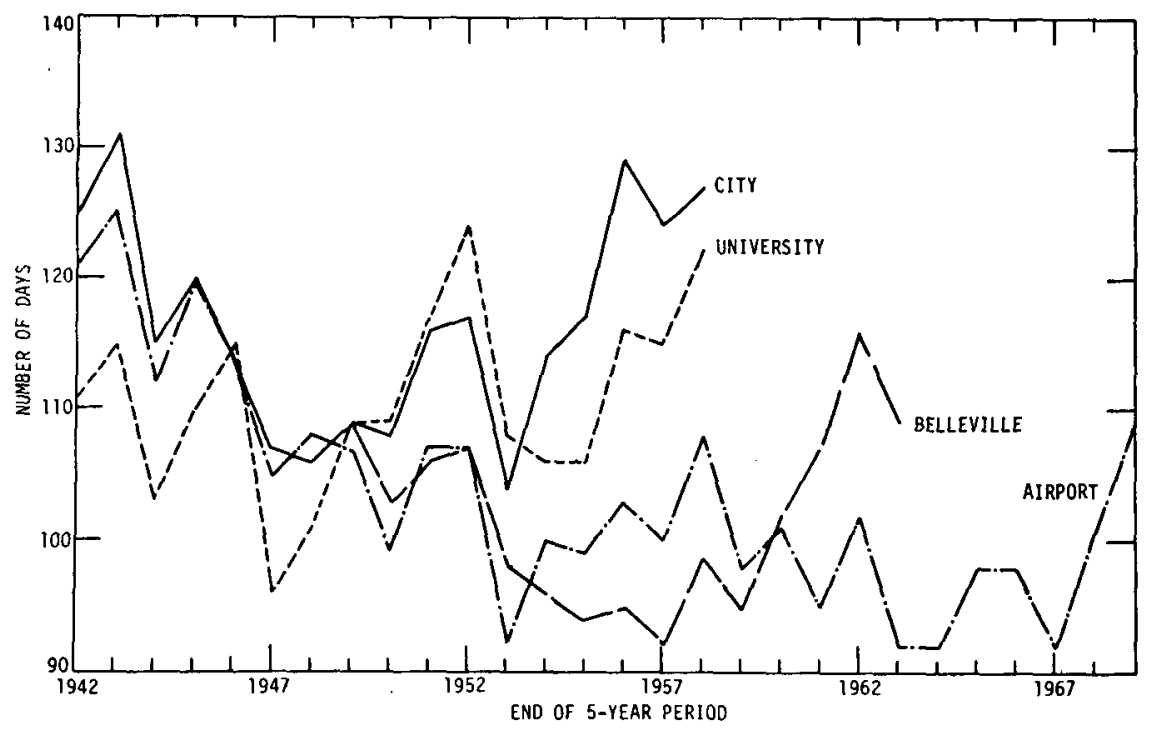

FIG. 10. Summer thunder days, 5-year moving totals.

and the summer values for 1942-69 are presented in Fig. 10 to exhibit the temporal trends. General similarity in the curves for the three St. Louis stations is evident in the 1938-45 period, but thereafter, marked upward changes in frequency are apparent at STL and UNI. Downwind, BLV (Fig. 1) from 1949 (the start of quality records) to 1956 had values which agreed with those upwind at APT, but after 1956 the BLV values also began to increase. Unfortunately, cessation of the thunder-day records at BLV occurred in 1964 and at STL and UNI in 1959. Nevertheless, the timetrend results reveal that stations in St. Louis and immediately downwind underwent marked increases in summer thunder days that generally began in the 194656 period. Summer thunder-day values over the city as compared to the APT represented increases of $20-25 \%$.

The availability of only 10 thunder-day data stations, several without overlapping quality data periods, made mapping of the average thunder-day patterns difficult. However, a short-period pattern was derived for 195158 because six of the stations in the immediate St. Louis area had quality records for this period. STL had the highest average with 24 thunder days (Fig. 11). Spatial patterns for other seasons are not presented because of



líg. 11. Pattern of average summer thunder days, 1951-68. their general uniformity. The predominance of apparent urban-effect thunderstorms in the summer season at St. Louis has been revealed elsewhere (Changnon $e t$ al., 1971).

Using available data for the 1941-68 period, average thunder-day patterns were derived for the 9 wettest summers, 9 driest summers, and the 10-near-normal rainfall summers in the 1941-68 period. An urban high was found in all types of summers, but was greatest in the wet summers. However, the urban high extended farther downwind of EDV and BLV in the dry summers.

Data from the entire period of joint operation of the STL and APT first-order stations (1939-57) were used to compare "solo" thunderstorm days. Solo days were those when one station had thunderstorms and the other had none. The summer APT solo values were considered to represent natural (rural) unaffected frequencies, and differences between these and the STL (urban) solo frequencies are considered indicative of urban effects. As shown in Table 16, there were 724 days with thunderstorms at both stations, but STL had 37 more solo days in 19 years, a difference that tested as not significant. However, the difference in the summer season of 38 thunder days, an average of 2 per year and an increase of $57 \%$, was quite significant.

In the 1950-June 1958 period STL had 62 solo summer thunder days, whereas the APT has only 28 , a difference of 34 days, an average of 4 per summer. Thus, most of the summer solo day difference existed in the latter portion of the period of joint operation of these two stations. Inspection of their frequencies by the four 6-hr periods of the day in the 1950-58 period appears in Table 17. Decidedly larger ratios occur in the 6-hr periods ending at 0600,1200 and 1800, indicating that the urban effects are active during the early morning 
TABLE 16. Total and solo thunder-day frequencies for upwind airport station and city station, 1939-57.

\begin{tabular}{|c|c|c|c|c|c|}
\hline Season & $\begin{array}{c}\text { Thunder days } \\
\text { at both. } \\
\text { stations }\end{array}$ & $\begin{array}{c}\text { City solo } \\
\text { thunder days }\end{array}$ & $\begin{array}{l}\text { Airport solo } \\
\text { thunder days }\end{array}$ & $\begin{array}{c}\text { Percentage dif- } \\
\text { ference in solo } \\
\text { days } \\
\text { City } \div \text { Airport }\end{array}$ & Significant $t$ scores* \\
\hline $\begin{array}{l}\text { Winter } \\
\text { Spring } \\
\text { Summer } \\
\text { Fall }\end{array}$ & $\begin{array}{r}33 \\
236 \\
344 \\
111\end{array}$ & $\begin{array}{r}8 \\
42 \\
105 \\
36\end{array}$ & $\begin{array}{r}6 \\
57 \\
67 \\
24\end{array}$ & $\begin{array}{l}+33 \\
-26 \\
+57 \\
+50\end{array}$ & $\begin{array}{l}\text { Not significant } \\
\text { Not significant } \\
2.492(0.025) \\
1.336(0.10)\end{array}$ \\
\hline Annual & 724 & 191 & 154 & +24 & Not significant \\
\hline
\end{tabular}

* 1-tail significance level (in parentheses).

and daytime periods. The apparent urban effect on localized thunderstorm occurrences in the morning hours agrees with the LaPorte findings (Changnon, 1968).

\section{b. Hail days}

Point-to-point comparisons of hail-day frequencies to derive meaningful temporal trends are difficult because of the low point incidence of hail. Therefore, regional total hail-day frequencies for the 1944-63 period (one with several stations with quality data) were determined from totals at three "upwind stations," and these were compared with those developed from three "downwind stations." The 5-year totals for these two areas (Fig. 12a) show that the total for the 1944-48 period was 14 at the Major Effect Area stations, as compared to 26 hail days in the three-station Upwind Area. In the succeeding 5-year periods, the Major Effect Area had many more total hail days (8 in 1949-53, 27 in 1954-58, and 14 in 1959-63). Comparisons of the summer hail results (Fig. 12b) with the summer thunder-day temporal results (Fig. 10) reveals that the apparent urban-related increases in thunderstorms began around 1945 and the hail day increases began in the late 1940's.

The spatial analyses of average annual and summer hail-day patterns (Fig. 13) were based on available data for 1949-65, the most recent period with a large number of stations with quality data. The marked downwind increases in summer hail days is clearly revealed with 15 days at EDW and 13 at BLV. Non-summer hail values in the area were very uniform during this 17-year period with September-May values at APT of 36 days, 32 at UNI, 38 at STL, 35 at BLV, and 38 at EDW. The high hail-day values to the north are a part of a macroscale high incidence area extending from Missouri across southcentral Illinois (Huff, 1961; Stout and Changnon, 1968).

Average hail-day patterns for the 9 driest summers, 9 wettest summers, and 10 near-normal rainfall summers in the 1941-68 period were derived. Downwind maxima were found in all types of summers, with the maxima to the NE of the city (EDW) in the wet and near-normal summers, but to the SE in the dry summers.
Comparisons of the seasonal hail-day values of upwind APT and STL (Minor Effect Area) and EDW in the Major Effect Area (Fig. 1) were performed to test for any statistical significance in their differences. Data employed were from the 1939-63 period when quality hail data were collected at all stations. Differences between the APT and STL values were slight and insignificant. Differences in STL vs EDW and APT vs EDW hail-day values in fall, winter and spring also were not significant, but the EDW summer value was significantly different. For example, in this 25-year period there was 1 summer day with hail at both the APT and EDW, but there was hail only at EDW on 17 days as compared to hail only at APT on 4 days. This 13-day difference in "solo" hail days produced a $t$-value for the binomial test of 2.695 which was significant at the 0.01 (1-tail) probability level. Apparent urbanrelated increases in hail occurred at all stations 5-20 mi downwind of St. Louis, but were not apparent at the urban station (STL) where thunder-day increases were noted to maximize.

The urban-related increases in hail days, as were the thunder increases, were largely restricted to the summer season. The summer hail-day frequencies at points downwind of St. Louis during the 1955-65 period were $100-200 \%$ greater than the point frequencies in and west of St. Louis. These large percentage increases in hail days at St. Louis are similar to those found at LaPorte (Changnon, 1968). Comparison of the actual increases in the summer frequencies of thunder days and hail days is revealing. The 1950-58 summer increases at STL in thunder days averaged 4 per year, and because this is an areal sampling at a point due to 6-mi audibility of thunder (Brooks, 1925), it represents

TABLE 17. Temporal distribution of solo summer thunderstorms at St. Louis City (urban-only) and Airport (rural-only) for 1950-58.

\begin{tabular}{|c|c|c|c|c|}
\hline \multirow{2}{*}{$\begin{array}{c}\text { Solo } \\
\text { thunderstorm } \\
\text { days }\end{array}$} & \multicolumn{4}{|c|}{ Number of thunderstorms per 6 -hr period } \\
\hline & $0000-0600$ & $0600-1200$ & $1200-1800$ & $1800-2400$ \\
\hline City & 18 & 10 & 23 & 11 \\
\hline Airport & 6 & 4 & 8 & 10 \\
\hline Ratio, C/A & 3.0 & 2.5 & 2.9 & 1.1 \\
\hline
\end{tabular}




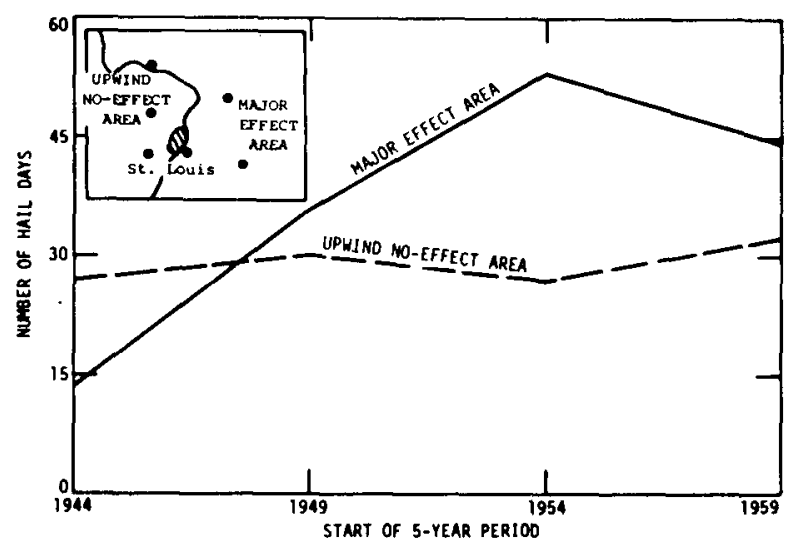

a.



b.

Fig. 12. Average 5-year frequency of total hail days, a., and summer hail days, b., in upwind and downwind areas (based on three stations in each area).

an additional 4 thunder days $(20 \%$ more than in noeffect area) over a $113-\mathrm{mi}^{2}$ area. The Major Effect Area, as defined by three points (Fig. 12), encompassed an area of $150 \mathrm{mi}^{2}$, and the area hail-day increase in the 1950-58 period was 8 (9 upwind vs 17 downwind), an average of nearly 1 day per year. Thus, on a regional basis, the average summer increase in days with thunder is greater than the hail increase (4 days to 1 day), although percentage-wise the hail increase is greater, $189 \%$ vs $20 \%$.

Although no direct cause-and-effect relationships can be shown for these thunder and hail increases and the potential effects from the urban-industrial complex at St. Louis, there is reasonably convincing evidence that these severe weather increases are urban-related because of the coherence in the temporal shifts of hail and thunder plus the juxtaposition of the increases with respect to the urban area.

\section{Summary and conclusions}

Specific atmospheric measurements of urban effects on weather that may extend considerably above the ground level and thereby lead to alterations in precipitation processes do not exist in historical records. Thus, evaluation of an urban effect on surface precipitation is difficult and is left to indirect statistical and circumstantial evidence. Assumptions must be made that: 1) any urban effect reacts on the local atmosphere so as to produce changes in surface precipitation conditions over and/or downwind of the urban complex (with downwind defined by the motions and durations of rainproducing elements crossing the urban complex); 2) that precipitation conditions in the area surrounding the urban and downwind potential effect area are representative of the climatic background (no effect) and 3) urban effects on precipitation lead to temporal increases detectable during the period of climatic records. Data from the basic effect and no-effect areas, whether analyzed on a regional, temporal, or point-topoint basis, become the basis for examining spatial and/or temporal changes in precipitation at a city. Unfortunately, pattern analyses, a primary standard climatic analytical tool, are difficult to test statistically, and yet lend themselves to meaningful urban rainfal investigations. Statistical tests of regional and point differences can also be applied on the basis of the above three assumptions.

A detailed climatic study was made of urban effects in the St. Louis area, based on long-term records of precipitation, severe local weather events (thunderstorms, hail, heavy rainfall), and related weather conditions within a radius of $50-75 \mathrm{mi}$ of the central city. Major emphasis was placed upon the 1941-68 period when the most satisfactory distribution of raingaging stations was in operation. Analyses were made of total precipitation on a monthly and seasonal basis; the frequency and intensity of daily rainfall; frequency of thunderstorms, hail, and severe rainstorms; thunderstorm rainfall amounts; weekday-weekend occurrence of precipitation (evidence of industrial-induced effects); diurnal rainfall distributions; possible differential urban effects in wet and dry periods; and the relationship between urban effects and synoptic weather conditions.

Results of the various analyses led to the conclusion that the urban-industrial area of St. Louis definitely affects the distribution of precipitation in and downwind of the central city. Evidence of a localized increase in total seasonal precipitation was found in all seasons, but was strongest in summer. The center of the urbaninduced high is located only 8-10 mi ESE of the center of the city. This suggests a possible intensification of cloud updrafts over the city from the heat island, resulting in an accumulation of water aloft, followed by a rapid release of accumulated water as the intensifying source disappears east of the city. Seasonal time-trend analyses indicated an intensification of the urban- 
induced high with progressing time, particularly during the last 10-15 years.

Spatial analyses of monthly precipitation patterns showed the strongest evidence of an urban effect in May, June, July and August. Indications were that rainfall was being intensified both in and downwind of the city in July. Time-trend analyses of monthly precipitation (April-September) also indicated that the downwind high was intensifying with progressing time.

Analyses were performed to separate the natural and urban components of summer rainfall in the St. Louis region. Results indicated that the urban-induced increase averaged approximately $10 \%$ in the downwind effect area during the 1941-68 period with values at individual stations ranging from $6-15 \%$.

Analyses of urban effects in relatively wet, dry, and moderate summers in the 1941-68 period indicated that urban-effect mechanisms for increasing rainfall downwind of the city were most effective in wet summers. In the dry summers, evidence was found of an urbaninduced suppression effect on the naturally occurring rainfall.

Studies of daily precipitation and heavy rainstorm occurrences indicated that urban-effect mechanisms were most active in increasing rainfall in the downwind area on days when the natural rainfall was of moderate to heavy intensity. Diurnal analyses indicated that the urban intensification is greatest during the afternoon peak of diurnal heating. Analyses of weekday-weekend relations in the warm season revealed a statistically significant greater frequency of rain occurrences per weekday than per weekend day in the Major Effect Area. Furthermore, the Major Effect Area averaged $11 \%$ more rainfall on weekdays than the two control areas, compared with $4 \%$ greater on weekends. Thus, the weekday-weekend differences provide strong evidence that the downwind high is urban-induced rather than the result of local topographic effects.

Synoptic analyses indicated that the summer rainfall high in the Major Effect Area results primarily from a strong tendency for rain from cold front storms to maximize there. A less pronounced trend was found for squall-line storms to maximize in the Major Effect Area.

Studies of the frequency of thunderstorm days indicated an urban-induced increase in and immediately downwind of the central city. This apparent urban effect occurred primarily in summer and intensified with progressing time beginning in the 1940's. The greatest relative frequency of urban-isolated storms existed in the morning hours, suggesting that thermal input from the city is a major causative factor.

Analyses of hail-day occurrences showed a downwind high in the same general area as the urban-induced rainfall maximum. The distance lag between the appearance of the urban-induced thunderstorm and hailstorm highs would be expected in view of the time lag from development of thunderstorms until intensification to the hail stage takes place.

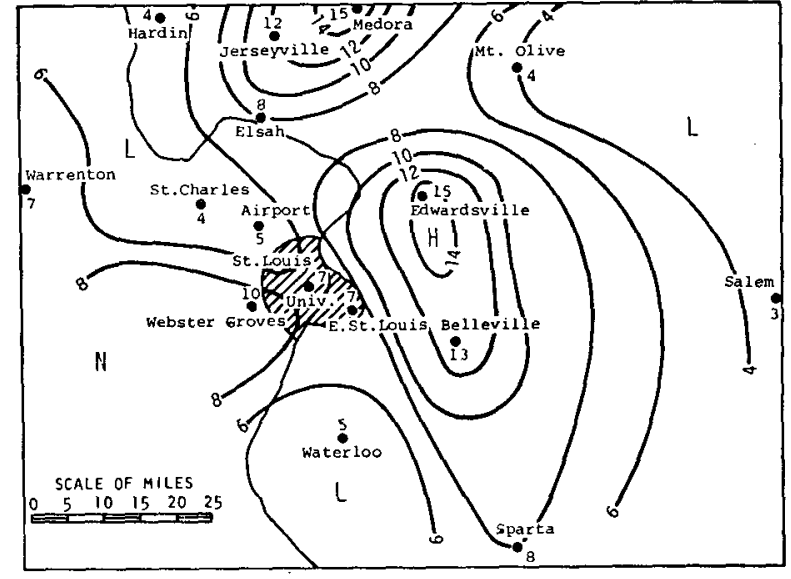

a.

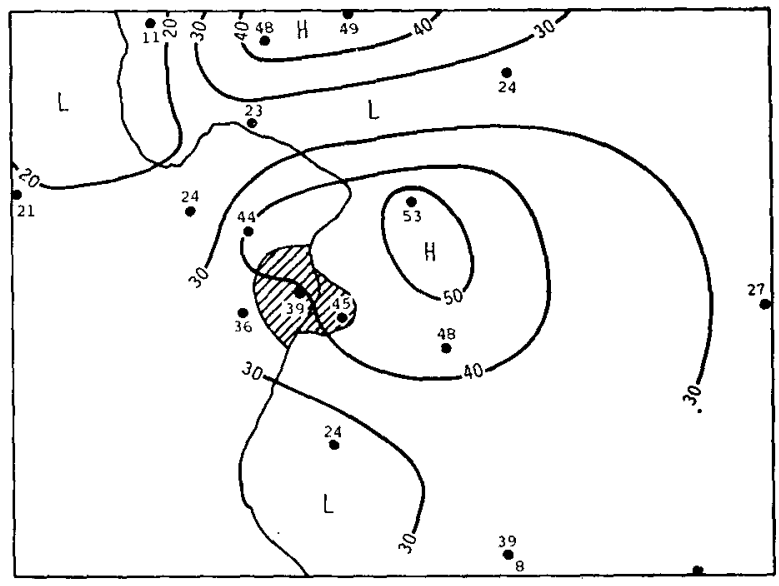

b.

Fig. 13. Hail day patterns, 1949-65: summer, a., total, b.

Overall, the results of the St. Louis climatic analyses showed varying degrees of summer season increases over but largely downwind of the city in all forms of precipitation. Downwind located summer changes in the 1941-68 period included: 1 ) average seasonal rainfall $[$ area $=+10 \%$, point differences $=+6$ to $+15 \%$; 2) average wet season rainfall [point differences $=+11$ to $+18 \%$ ]; 3) average dry season rainfall [point differences $=-5$ to $-9 \%]$; 4) area average moderate rain days $[+8 \%] ; 5)$ area average heavy rainstorms $[+31 \%]$; 6) weekday vs weekend area rain-day averages $[+13 \%] ; 7)$ point differences in average afternoon rainfall $[43 \%] ; 8)$ average thunder-day frequencies [point differences $=+20$ to $+25 \%$ ]; and 9) area average hail-day frequencies $[+35 \%]$. The summer increases in the downwind area in area average rainfall, rain-day frequencies on weekdays, thunder-day frequencies, and hail-day frequencies were all statistically significant to 1 -tail probabilities $\leqslant 0.02$. In addition, all forms of pattern analyses supported 
positive departures in the downwind area. The simultaneity of all these positive aberrations in a single area located adjacent to and downwind of St. Louis reflects a coherence that, although not statistically testable as a combination of positive events, together become very strong circumstantial evidence of the presence of urban effects on summer precipitation.

Acknowledgments. This research was supported by funds from the Atmospheric Sciences Section of the National Science Foundation under Grant GA-18781. Elmer Schlessman and Mrs. Margaret Betchart supervised and performed much of the routine data analyses. Timothy Lewis contributed substantially to the severe weather study. Griffith Morgan assisted in the synoptic weather analyses and Dr. Paul Schickedanz in statistical analyses performed in various phases of the research.

\section{REFERENCES}

Byers, H. R., and R. R. Braham, Jr., 1949: The Thunderstorm. U. S. Dept. of Commerce, Weather Bureau, $287 \mathrm{pp}$.

Brooks, C. E. P., 1925: 'The distribution of thunderstorms over the globe. Geophys. Mem., 3, 147-164.

Changnon, S. A., 1957: Thunderstorm-precipitation relations in Illinois. Rept. of Investigation 34, Illinois State Water Survey, Urbana, 24 pp.

-_, 1966: Method of evaluating substation records of hail and thunder. Mon. Wea. Rev., 95, 209-212.

-w, 1968: The LaPorte weather anomaly-fact or fiction? Bull. Amer. Meteor. Soc., 49, 4-11.

- 1969: Urban-produced thunderstorms at St. Louis and Chicago. Preprints Fifth Severe Local Storms Conf., Chicago, Amer. Meteor. Soc., 95-99.
- - , and F. A. Huff, 1961 : Studies of radar-depicted precipitation lines. Sci. Rept. 2, Contract AF 19(604)-4940, Illinois State Water Survey, Urbana, 63 pp.

- - - and R. G. Semonin, 1971: METROMEX: An investigation of inadvertent weather modification. Bull. Amer. Meteor. Soc., 52, 958-967.

-- and P. T. Schickedanz, 1971: Statistical studies of inadvertent modification of precipitation. Preprints Intern. Symp. Probability and Statistics in the Atmospheric Sciences, Honolulu, Amer. Meteor. Soc., 137-142.

Frederick, R. H., 1970: Preliminary results of a study of precipitation by day-of-the-week over eastern U. S. Preprints Second Natl. Conf. Weather Modification, Santa Barbara, Amer. Meteor. Soc., 215-220.

Hershfield, David M,, 1961: Rainfall frequency atlas of the United States. Tech. Paper No. 40, U. S. Dept. of Commerce, Weather Bureau, 115 pp.

Huff, F. A., 1961 : Correlation between summer hail patterns in Illinois and associated climatological events. Res. Rept. 10, Crop-Hail Insurance Actuarial Association, Chicago, $17 \mathrm{pp}$.

-_, 1971: Distribution hourly precipitation in Illinois. Circ. 105, Illinois State Water Survey, Urbana, 23 pp.

-- , and S. A. Changnon, 1970: Urban effects on daily rainfall distribution. Preprints Second Natl. Conf. Weather Modificacation, Santa Barbara, Amer. Meteor. Soc., 215-220.

Lawrence, E. N., 1971: Day-of-the-week variation on weather. Weather, 26, 386-391.

Stout, G. E., and S. A. Changnon, 1968: Climatography of hail in the central United States. Res. Rept. 38, Crop-Hail Insurance Actuarial Association, Chicago, $49 \mathrm{pp}$.

Towery, N. G., and S. A. Changnon, 1970: Characteristics of hail-producing radar echoes in Illinois. Mon. Wea. Rev., 98, 346-353.

Wadsworth, G. P., 1951 : A possible experimental design for testing the effectiveness of cloud seeding. Rept. for Geophysical Research Directorate, Cambridge Field Station, Mass., Contract $A F$ 19(122)-401. 